\title{
Evidence of Back Diffusion Reducing Cracking during Solidification
}

\author{
Jiangwei Liu ${ }^{1}$, Henrique Pinho Duarte ${ }^{2}$ and Sindo Kou ${ }^{2}$ \\ ${ }^{1}$ Central South University, Changsha, China; ${ }^{2}$ University of Wisconsin, Madison, WI
}

\begin{abstract}
Al-Mg alloys, despite their wide freezing temperature range $\Delta T_{f}$, can have good resistance to cracking during solidification. To help understand why, the mushy zone of $5086 \mathrm{Al}(\sim \mathrm{Al}-4.0 \mathrm{Mg})$ was quenched during arc welding and the cooling curve measured to locate the beginning of the original mushy zone (liquidus temperature $T_{L}$ ) and the end (eutectic temperature $T_{E}$ ). Since little eutectic was visible just slightly behind the beginning of the quenched mushy zone, little liquid was here in the original mushy zone, i.e., solidification already ended well above $T_{E}$. Since no dendrites were visible, either, and since the highest $\mathrm{Mg}$ content measured was well below the maximum solubility in
\end{abstract} solid $\mathrm{Al}, C_{S M}(17.5 \mathrm{wt} \% \mathrm{Mg})$, microsegregation was very mild here in the original mushy zone. These results suggest significant Mg back diffusion occurred during solidification (because of very high $C_{S M}$ ), causing: 1 . fraction solid $f_{S}$ to increase much faster with decreasing temperature $T, 2 . \Delta T_{f}$ to narrow down, and 3. dendritic grains to bond together extensively $\left(f_{S} \approx 1\right)$ to resist intergranular cracking earlier (well above $T_{E}$ ). Since $\left|d\left(f_{S}\right) / d T\right|$ increased, $\left|d T / d\left(f_{S}\right)^{1 / 2}\right|$ decreased to decrease the crack susceptibility index, i.e., the maximum $\left|d T / d\left(f_{S}\right)^{1 / 2}\right|$. All these changes reduce the crack susceptibility. For comparison, $2014 \mathrm{Al}(\sim \mathrm{Al}-4.4 \mathrm{Cu})$ was also quenched during arc welding. At the end of the quenched $2014 \mathrm{Al}$ mushy zone, continuous eutectic, dendrites and microsegregation were all very clear. Thus, solidification ended at $T_{E}$ and thin liquid films still separated grains at the end of the original mushy zone to allow intergranular cracking. Calculated $T-\left(f_{S}\right)^{1 / 2}$ curves showed the index is reduced significantly by back diffusion in $\mathrm{Al}-4.0 \mathrm{Mg}$ $(\sim 5086 \mathrm{Al})$ but not in $\mathrm{Al}-4.4 \mathrm{Cu}(\sim 2014 \mathrm{Al})$. 


\section{Introduction}

Cracking of an alloy during solidification is a serious defect. In welding it is called solidification cracking [1]. In casting it is called hot tearing [2, 3]. Al alloys are known to be susceptible to cracking during solidification in welding and casting [1-3]. It has long been a puzzle why Al-Mg alloys can have good weldability despite their very wide freezing temperature range. Because a liquid alloy freezes over a temperature range, a weak semisolid region, called the mushy zone, exists between the liquid pool and the completely solidified alloy. For most $\mathrm{Al}$ alloys the freezing temperature range is $\Delta T_{f}=T_{L}$ $-T_{E}$, where $T_{L}$ is the liquidus temperature and $T_{E}$ the eutectic temperature. An alloy with a wider $\Delta T_{f}$ can be expected to have a wider weak mushy zone and hence a higher susceptibility to solidification cracking. Cracking occurs near the end of the mushy zone, where a small amount of liquid still can exist as thin liquid films along grain boundaries to keep grains from bonding together firmly to resist intergranular cracking under tension. Tension is induced when free contraction due to solidification shrinkage and thermal contraction is obstructed, e.g., by rigid workpiece in welding or by rigid mold walls in casting.

The prominent RDG model of Rappaz, Drezet and Gremaud [4] was the first hot tearing model with a physically sound basis. However, the grain boundary, where cracking occurs, was not yet taken into account. Kou [5] developed a model focusing on the grain boundary. Consider two columnar dendritic grains growing side by side in the same axial growth direction. The following three factors can be relevant: 1. lateral separation of the grains from each other under tension to cause cracking, 2. lateral growth 
of the grains toward each other to bond together to resist cracking, and 3. liquid feeding along the grain boundary in the opposite direction of axial growth to resist cracking.

Consider a volume element $\Omega$ between the two grains near the end of the mushy zone, where cracking occurs. The net volume expansion rate of $\Omega$ is that due to lateral grain separation minus that due to lateral grain growth. The net volume flow rate of liquid entering $\Omega$, on the other hand, is the volume flow rate of liquid entering $\Omega$ minus that leaving $\Omega$. When the net volume expansion rate of $\Omega$ exceeds the net volume flow rate of liquid entering $\Omega$, a void (i.e., crack) can occur in $\Omega$ [5] if crack initiation sites are available, such as folded oxide films, micropores or the external surface of the weld or casting $[3,6,7]$.

Kou [5] showed that near $f_{S}=1$ the lateral growth rate of grains toward each other to bond together to resist cracking is proportional to $\left|d\left(f_{S}\right)^{1 / 2} / d T\right|$, where $T$ is temperature and $f_{S}$ fraction of solid. Kou [5] pointed out that $\left|d T / d\left(f_{S}\right)^{1 / 2}\right|$ near $\left(f_{S}\right)^{1 / 2}=1$ can be considered as an index for the crack susceptibility for the following three reasons. First, the higher $\left|d T / d\left(f_{S}\right)^{1 / 2}\right|$ is, the slower the two neighboring columnar grains can grow toward each other to bridge together and resist cracking. Second, with slow lateral growth the columnar grains can grow very long without bridging. This means the intergranular liquid channel can be very long and hence difficult for liquid to flow through it (due to viscosity of liquid [8]) to feed shrinkage and resist cracking. Third, a long intergranular liquid channel can act as a long sharp notch to promote crack initiation. Thus, $\left|d T / d\left(f_{S}\right)^{1 / 2}\right|$ near $\left(f_{S}\right)^{1 / 2}=1$ can be used as an index for the susceptibility to cracking during solidification. For binary $\mathrm{Al}$ alloys and commercial wrought $\mathrm{Al}$ alloys, 
the maximum $\left|d T / d\left(f_{S}\right)^{1 / 2}\right|$ occurs near $\left(f_{S}\right)^{1 / 2}=1[5]$. Thus, the maximum $\left|d T / d\left(f_{S}\right)^{1 / 2}\right|$ can also be used as the crack susceptibility index [9].

The validity of using the maximum $\left|d T / d\left(f_{S}\right)^{1 / 2}\right|$ as the index for the crack susceptibility was verified [9]. The curves of $T v s .\left(f_{S}\right)^{1 / 2}$ can be calculated based on the composition of an alloy or a weld using Pandat [10], PanAluminum [11] and the Scheil solidification model (no diffusion), which is also called the Gulliver-Scheil solidification model $[12,13]$. First, a filler metal that reduced the maximum $\left|d T / d\left(f_{S}\right)^{1 / 2}\right|$ of an alloy was shown to actually reduces its solidification cracking in welding, e.g., filler metal $4145 \mathrm{Al}$ for welding $2014 \mathrm{Al}$ and filler metal $4043 \mathrm{Al}$ for welding $6061 \mathrm{Al}$ and $7075 \mathrm{Al}$. Second, the maximum $\left|d T / d\left(f_{S}\right)^{1 / 2}\right|$ increased in the order of 2219, 2014, 2024, 6061 and $7075 \mathrm{Al}$, consistent with their ranking in crack susceptibility tests.

However, the predicted crack susceptibility of Al-Mg alloys was too high, higher than that of $\mathrm{Al}-\mathrm{Cu}$ alloys. This is because the maximum freezing temperature range $\left(\Delta T_{f}\right.$ $=T_{m}-T_{E}$, where $T_{m}$ is the melting point of $\left.\mathrm{Al} 660{ }^{\circ} \mathrm{C}\right)$ is much wider for $\mathrm{Al}-\mathrm{Mg}\left(210{ }^{\circ} \mathrm{C}\right)$ than for $\mathrm{Al}-\mathrm{Cu}\left(112{ }^{\circ} \mathrm{C}\right)$ and this significantly increases the maximum $\left|d T / d\left(f_{S}\right)^{1 / 2}\right|$ of Al-Mg alloys. However, Cross et al. [14] and Rosenberg et al. [15] showed less cracking during solidification for $\mathrm{Al}-\mathrm{Mg}$ alloys than $\mathrm{Al}-\mathrm{Cu}$ alloys, even though $\mathrm{Al}-\mathrm{Mg}$ alloys are expected to be more crack susceptible because of their much wider $\Delta T_{f}$. Instead of using the Scheil model and assuming no back diffusion, the following equation of Kurtz and Fisher [16] was used to include back diffusion:

$$
f_{S}=\frac{1}{1-2 \alpha^{\prime} k}\left[1-\left(\frac{T_{m}-T}{T_{m}-T_{L}}\right)^{\frac{1-2 \alpha^{\prime} k}{k-1}}\right]
$$

where 
$\alpha^{\prime}=\alpha\left[1-\exp \left(-\frac{1}{\alpha}\right)\right]-\frac{1}{2} \exp \left(-\frac{1}{2 \alpha}\right)$

$\alpha=\frac{4 D_{S} t_{f}}{\lambda_{2}^{2}}$

$\alpha^{\prime}$ is the diffusion parameter, $k$ equilibrium segregation coefficient, $T_{m}$ melting point of pure Al, $T_{L}$ liquidus temperature, $D_{S}$ diffusion coefficient of solute in solid dendrites, $t_{f}$ local freezing (solidification) time, and $\lambda_{2}$ secondary dendrite arm spacing. In Eq. (1) the solidus and liquidus lines are assumed straight lines, i.e., $k$ is constant. Without diffusion, $\alpha=\alpha^{\prime}=0$ and Eq. (1) reduces to the simple Scheil equation $[12,13]$.

Curves of $T$ vs. $\left(f_{S}\right)^{1 / 2}$ were calculated using Eq. (1). It was found that the maximum $\left|d T / d\left(f_{S}\right)^{1 / 2}\right|$, that is, the crack susceptibility index, is reduced by back diffusion. The higher the diffusion parameter $\alpha^{\prime}$ is, the greater the reduction [17]. The crack susceptibility curve for a binary alloy system is a curve of the crack susceptibility vs. the solute content. The curve is $\lambda$-shaped, that is, with a peak at an intermediate solute content [1]. When the maximum $\left|d T / d\left(f_{S}\right)^{1 / 2}\right|$ is plotted against the solute content of a binary Al alloy, a $\lambda$-shaped crack-susceptibility curve was obtained, consistent with the $\lambda$-shaped curves observed in crack-susceptibility tests of binary Al alloys. The peak of the crack-susceptibility curve shows the solute content most susceptible to cracking and the level of the crack susceptibility. With the back diffusion parameter $\alpha^{\prime}$ raised from 0 (no diffusion) to $0.025,0.050$ and 0.075 , for instance, the peak of the crack-susceptibility curve decreased in magnitude and shifted to a higher solute content. The decrease was much greater with Al-Mg alloys than Al-Cu alloys. 
The objectives of the present study were to: 1. develop an experimental procedure to quench the mushy zone during welding, and 2. use the quenched-in microstructure and microsegregation of the mushy zone to explain why Al-Mg alloys, despite their much wider freezing temperature range $\Delta T_{f}$, can be less susceptible to solidification cracking than Al-Cu alloys.

\section{Experimental Procedure}

\subsection{Welding}

2000-series and 5000-series Al alloys are widely used commercial wrought Al alloys. The former are essentially binary Al-Cu alloys with about 2 to $6 \mathrm{wt} \% \mathrm{Cu}$ and the latter essentially binary Al-Mg alloys with 1 to 5 wt\% Mg. $2014 \mathrm{Al}$ ( Al-4.4Cu) was selected as a representative alloy for Al-Cu alloys, so was $5086 \mathrm{Al}(\sim \mathrm{Al}-4.0 \mathrm{Mg})$ for $\mathrm{Al}-$ Mg alloys. The chemical compositions of the two alloys used are shown in Table 1. The workpiece was in the form of a thin sheet, $102 \mathrm{~mm}$ by $102 \mathrm{~mm}$ by $2 \mathrm{~mm}$ in the case of $2014 \mathrm{Al}$ and $102 \mathrm{~mm}$ by $102 \mathrm{~mm}$ by $1.6 \mathrm{~mm}$ in the case of $5086 \mathrm{Al}$. Before welding, the workpiece surface was cleaned with a stainless steel brush to remove oxide films and then rinsed with acetone.

Bead-on-plate welding was conducted without a filler metal using gas-tungsten arc welding (GTAW), which is also called tungsten-inert gas (TIG) welding. The workpiece was welded along its centerline, starting from about $10 \mathrm{~mm}$ away from its leading edge and proceeding inward. The welding conditions were as follows: direct current electrode negative (DCEN), $4.25 \mathrm{~mm} / \mathrm{s}$ torch travel speed, $13 \mathrm{~V}$ welding voltage, and pure Ar gas shielding. The welding current was $100 \mathrm{~A}$ for $2014 \mathrm{Al}$ and $80 \mathrm{~A}$ for $5086 \mathrm{Al}$. Since 5086 
Al (1.6 mm thick) was thinner than $2014 \mathrm{Al}$ (2 mm thick), the welding current was reduced from $100 \mathrm{~A}$ to $80 \mathrm{~A}$ in order to keep the weld width close to that of $2014 \mathrm{Al}$.

In GTAW, weld penetration is deeper with the DCEN polarity [1], which is desirable in thick-plate welding. Although the present study involved thin-sheet welding, DCEN was still selected because a deeper-penetrating heat source is known to promote 2diemnsional heat flow in the workpiece [1]. Although He is often used in GTAW-DCEN of Al plates, the higher arc power (associated with the higher ionization energy of $\mathrm{He}$ than Ar) can be excessive for welding thin Al sheets. Thus, Ar was used as the shielding gas.

\subsection{Quenching}

The mushy zone was quenched with molten Woods metal during welding. Kou and Le [18] first quenched Al alloys during gas-tungsten arc welding by pouring ice water onto the weld pool and its surrounding area. The microstructure around the weld pool during welding was quenched-in, including the partially melted grains around the weld pool, dendrites in the mushy zone behind the weld pool, and heterogeneous nuclei in the weld pool. Grain refining mechanisms in welds, such as grain detachment, dendrite fragmentation and heterogeneous nucleation, were established based on the quenched microstructure [18-20]. Kou and Le [21] first quenched stainless steel during gastungsten arc welding with molten tin. In spite of the significantly higher melting point of tin $\left(232{ }^{\circ} \mathrm{C}\right)$ than ice, tin quenching was more effective because there was no vapor (steam) to keep the liquid from touching the area around the weld pool. Molten Sn (about $250{ }^{\circ} \mathrm{C}$ in temperature), however, is too warm for quenching $\mathrm{Al}$ welds. Thus, it was decided to use molten Woods metal, which would allow quenching at a lower 
temperature and without steam. According to the supplier [22], the melting temperature of Woods metal is only $70{ }^{\circ} \mathrm{C}$. Molten Woods metal, about $50 \mathrm{ml}$ in volume and $70-80{ }^{\circ} \mathrm{C}$ in temperature, was poured from a $100 \mathrm{ml}$ glass beaker onto the weld pool to quench the mushy zone behind it. The authors are unaware of the use of Woods metal for quenching in previous welding studies.

\subsection{Temperature Measurements}

Temperature measurements were conducted during welding using a K-type ungrounded thermocouple with a stainless steel sheath of $0.5 \mathrm{~mm}$ outer diameter. It was mounted on a mechanical device to suddenly push it to a predetermined lower position. The thermocouple was positioned at $5 \mathrm{~mm}$ above the workpiece before plunging. The temperature data was recorded at $20 \mathrm{~Hz}$ using a computer-based data acquisition system together with the software Labview.

Fig. 1 illustrates how quenching and cooling-curve measurement were conducted during welding. Fig. 1a is a top view showing the weld pool and the mushy zone behind it during the welding of an alloy workpiece. The semisolid microstructure, including the partially melted zone around the pool and the mushy zone behind the pool, was constructed based on results from quenching Al welds with ice water during welding [16]. Since thermal undercooling is usually small in arc welding, the pool boundary can be taken as an isotherm at the liquidus temperature $T_{L}$ of the alloy. The beginning of the mushy zone (i.e., the trailing portion of the weld pool boundary) is at $T_{L}$ and the end is at the eutectic temperature $T_{E}$ of the alloy.

Fig. 1b is a vertical cross-section (that passes through the weld centerline and the axis of the tungsten electrode) showing the positions of the welding arc and thermocouple 
relative to the weld pool and the mushy zone. The thermocouple was plunged into the weld pool when the trailing portion of the weld pool moved under the thermocouple. Shortly after the liquid around the thermocouple solidified completely, molten Woods metal was poured onto the weld pool to quench the mushy zone behind it, as illustrated in Fig. 1c. Initially, welding was conducted from above the workpiece, but the torch stood in the way of the thermocouple and Woods metal. Thus, it was subsequently decided to weld from below.

The pouring action caused the arc to extinguish by itself. The carriage carrying the torch was then stopped and the power source turned off. Sometimes, the arc reinitiated itself just before the power source was turned off. For comparison, welding was also conducted under identical welding conditions without quenching.

\subsection{Microstructure and Microsegregation}

After welding, the welds were cut, polished and etched with Keller's solution for 5 seconds to reveal the microstructure of the quenched mushy zone. Both optical microscopy and scanning electron microscopy (SEM) were used.

To determine the microsegregation in the quenched mushy zone, a Cameca SXFiveFE model electron probe micro analyzer (EPMA) was used, which is a state-ofthe-art field emission machine for quantitative analysis and X-ray mapping at high spatial resolution. Up to five Wavelength Dispersive Spectrometers (WDS) could be fit into the microprobe for high precision quantitative analysis. The beam diameter used was 80 $100 \mathrm{~nm}$, the voltage and current being $18 \mathrm{kV}$ and $32 \mathrm{nA}$, respectively. The volume below the sample surface affected by the beam was $2 \mu \mathrm{m}$ in diameter. EPMA was done using the $\mathrm{Ka}$ x-ray lines of $\mathrm{Mg}, \mathrm{Si}, \mathrm{Mn}, \mathrm{Fe}, \mathrm{Al}, \mathrm{Cu}$ and $\mathrm{Cr}$. Crystals used were: LTAP for $\mathrm{Mg}$ 
and $\mathrm{Si}$, LLIF for $\mathrm{Fe}, \mathrm{Cu}$ and $\mathrm{Cr}$, and PET for Mn. The counting times (Peak/Background in seconds/seconds) were $\mathrm{Al}, \mathrm{Cu}$ and $\mathrm{Mn}$ for 10/10, $\mathrm{Mg}$ and $\mathrm{Fe}$ for 4/4, and $\mathrm{Si}$ and $\mathrm{Cr}$ for $3 / 2$.

The samples were polished but not etched, in order not to affect the composition measurements by EPMA. EPMA was conducted over an area of $200 \mu \mathrm{m}$ by $200 \mu \mathrm{m}$ covered by a grid of 21 horizontal lines by 21 vertical lines, that is, 441 grid points. This kind of approach is common for analyzing microsegregation in cast alloys [23, 24].

\section{Results and discussion}

\subsection{Quenching}

Fig. 2 shows the results of quenching 2014 Al during welding. Fig. 2a shows the measured cooling curve. Before being plunged into the weld pool, the thermocouple was already recording a temperature around $100{ }^{\circ} \mathrm{C}$ because, as mentioned previously, the thermocouple was $5 \mathrm{~mm}$ above the workpiece. Thus, it was already heated by radiation and convection from the workpiece and the weld pool before being plunged into the weld pool. For $2014 \mathrm{Al}, T_{L}=640.3{ }^{\circ} \mathrm{C}$ and $T_{E}=510.5^{\circ} \mathrm{C}$ based on thermodynamic calculation using commercial software Pandat [10] and Al-alloy database PanAluminum [11].

As shown, when the thermocouple was plunged into the weld pool, the temperature rose sharply to over $800{ }^{\circ} \mathrm{C}$. For convenience of discussion, the time at about $0.5 \mathrm{~s}$ before thermocouple plunging is taken arbitrarily as time $0 \mathrm{~s}$ in Fig. 2a. This is just a reference point and it does not affect the discussion. The local solidification time $t_{f}$ (time to cool through the freezing temperature range, from $T_{L}$ to $T_{E}$ ) is $1.36 \mathrm{~s}$ and the average cooling rate during solidification is $95{ }^{\circ} \mathrm{C} / \mathrm{s}\left(=129.8{ }^{\circ} \mathrm{C} \div 1.36 \mathrm{~s}\right)$. As will be explained subsequently, the steady-state welding condition was already reached before the 
thermocouple was plunged. Thus, the time scale in Fig. 2a can be converted into a distance scale by being multiplied by the travel speed $4.25 \mathrm{~mm} / \mathrm{s}$. Thus, as shown in Fig. 2a, the length of the mushy zone is $5.78 \mathrm{~mm}(=1.36 \mathrm{~s} \times 4.25 \mathrm{~mm} / \mathrm{s})$, that is, the end of the mushy zone is at $5.78 \mathrm{~mm}$ behind the weld pool boundary.

Quenching took place at time $4 \mathrm{~s}$. The material surrounding the thermocouple already completely solidified before quenching, and it cooled down rapidly upon quenching. The mushy zone, which was warmer than the solidified material at the thermocouple, can be expected to cool down even faster during quenching to help preserve its microstructure. The warmer the material is before quenching, the higher the cooling rate during quenching becomes because the heat extraction rate is proportional to the temperature difference between the material and the coolant, that is, liquid Woods metal [8].

Fig. $2 \mathrm{~b}$ and c show the appearance of the quenched $2014 \mathrm{Al}$ weld. The thermocouple left a hole in the fusion zone after it was removed after welding. As shown, most of the liquid in the weld pool was pushed out by molten Woods metal during quenching. Some residual Woods metal remained near the pool boundary. The width of the weld is uniform, which indicates that, before quenching, welding already reached the steady-state or "quasi-stationary" condition [1]. In other words, the weld pool and the mushy zone no longer changed in shape or size during welding. Furthermore, the weld width at the top surface is essentially identical to that at the bottom surface, which indicates heat flow during welding was 2-dimensional. In other words, the same temperature distribution existed throughout the entire thickness of the workpiece and that the cooling curve was identical throughout the weld thickness. 
Solidification cracking is visible on both the top and bottom surfaces of the weld. When quenched with Woods metal, the mushy zone and its surrounding area in the workpiece suddenly shrank under solidification shrinkage and thermal contraction. However, free shrinking was not allowed because, as in common welding practice, the workpiece was clamped down tightly onto a rigid fixture. During quenching, cooling was instantaneous, so was the tensile strain induced in the mushy zone. Thus, along the centerline of the mushy zone, columnar grains growing in the welding direction were subjected to an instantaneous tensile strain in the lateral direction. According to the proposed criterion for solidification cracking shown in Eq. (1), cracking can occur if the columnar grains are separated from each other in the lateral direction too fast for them to grow laterally toward each other to bridge together and resist cracking. Likewise, cracking can occur if the lateral separation is too fast for liquid to flow through the channels between the columnar grains to feed shrinkage or grain separation and resist cracking.

Fig. 3 shows the results of quenching $5086 \mathrm{Al}$ during welding. For $5086 \mathrm{Al}, T_{L}=$ $640.3{ }^{\circ} \mathrm{C}$ and $T_{E}=450.5{ }^{\circ} \mathrm{C}$ based on thermodynamic calculation using Pandat [10] and PanAluminum [11]. This eutectic temperature is significantly lower than that of $2014 \mathrm{Al}$ $\left(T_{E}=510.5^{\circ} \mathrm{C}\right)$. From the cooling curve, it can be expected that the local solidification time $t_{f}$ is $1.88 \mathrm{~s}$, the average cooling rate during solidification $101{ }^{\circ} \mathrm{C} / \mathrm{s}\left(189.8{ }^{\circ} \mathrm{C} \div 1.88\right.$ $\mathrm{s})$, and the length of the mushy zone along its centerline $7.99 \mathrm{~mm}(=1.88 \mathrm{~s} \times 4.25 \mathrm{~mm} / \mathrm{s})$. However, as will be explained subsequently, the microstructure of the quenched $5086 \mathrm{Al}$ mushy zone showed solidification ended at $2.30 \mathrm{~mm}$ behind the quenched weld pool. 
Fig. $3 \mathrm{~b}$ and $\mathrm{c}$ show the appearance of the quenched $5086 \mathrm{Al}$ weld. The weld was unintentionally cut before photographing. So, an identical weld made with quenching but without thermal measurement is shown in Fig. $3 \mathrm{~b}$ and $\mathrm{c}$ and that is why no thermocouple hole is visible in Fig. 3b. More importantly, solidification cracking did not occur in 5086 Al during quenching. This is consistent with the lower crack susceptibility of Al-Mg alloys observed by Cross et al. [14] and Rosenberg et al. [15].

\subsection{Microstructure}

Fig. 4 shows the microstructure of the quenched mushy zone of 2014 Al. Fig. 4a shows the microstructure at the beginning of the quenched mushy zone. The quenched pool boundary is indicated by the broken white line, behind (i.e., to the right of) which is the quenched mushy zone. In the quenched mushy zone the light-etching phase is the Alrich dendrites and the dark-etching phase in the interdendritic area is the solid $\mathrm{Cu}$-rich eutectic. During solidification the interdendritic liquid formed the Al-rich phase first and finally the $\mathrm{Cu}$-rich eutectic upon further cooling to the eutectic temperature. So, the presence of eutectic at a location in the quenched mushy zone indicates the presence of liquid at the same location in the original mushy zone. The dendritic structure of the mushy zone is very fine at the quenched pool boundary because of the high cooling rate during quenching [2]. Fig. 4b shows the microstructure at the end of the quenched mushy zone, which is located at $5.78 \mathrm{~mm}$ behind the quenched pool boundary. The dendritic structure is coarser here than in Fig. 4a because a dendritic structure becomes coarser with increasing solidification time $t_{f}$, during which dendrite coarsening can occur [2]. Since the eutectic is essentially continuous everywhere here, continuous liquid films existed along grain boundaries at the end of the original mushy zone during welding. 
Liquid films along grain boundaries weaken bonding between grains, allowing intergranular cracking to occur under the tension induced by solidification shrinkage and thermal contraction.

Fig. 5 shows the microstructure in the fusion zone of $2014 \mathrm{Al}$ without quenching. The arc was turned off at the end of welding, and the last weld pool solidified without traveling, which is often called the weld crater. As shown, the fusion zone microstructure is somewhat finer at the crater boundary (Fig. 5a) than at $5.78 \mathrm{~mm}$ behind it (Fig. 5b). This is because the cooling rate was higher at the crater boundary than at $5.78 \mathrm{~mm}$ behind it. The weld pool cooled down immediately when the arc was turned off at the end of welding. However, the cooling rate was still much lower than that caused by quenching. Consequently, the dendritic structure at the crater boundary is much coarser than that at the quenched pool boundary (Fig. 4a). Also, as can be seen by comparing Fig. 5b with Fig. $4 \mathrm{~b}$, the eutectic (the dark-etching phase) is thinner and lighter in color in the former. This suggests that less eutectic is present because of $\mathrm{Cu}$ diffusion (from the solid eutectic to the surrounding Al-rich matrix) still occurred after solidification was over. Since diffusion is faster at the higher temperatures during solidification, $\mathrm{Cu}$ back diffusion from the interdendritic liquid into the Al-rich dendrites should be significant.

Fig. 6 shows the microstructure of the quenched mushy zone of 5086 Al. Fig. $6 a$ shows the microstructure at the beginning of the quenched $5086 \mathrm{Al}$ mushy zone. The broken white line again indicates the quenched pool boundary and the dark area on the left represents the weld pool liquid pushed out by liquid Woods metal during quenching. Again, the dendritic structure of the mushy zone is very fine because of the high cooling rate during quenching. More importantly, the quenched dendritic structure does not show 
a clear contrast between the light-etching Al-rich dendrites and the dark-etching interdendritic eutectic, nothing like the quenched dendritic structure of $2014 \mathrm{Al}$ (Fig. 4a). This is because less liquid was here and thus less eutectic formed from the liquid upon quenching. This suggests $\mathrm{Mg}$ back diffused from the interdendritic liquid into the Al-rich dendrites during solidification. Back diffusion causes the Mg content of the interdendritic liquid to drop. To maintain the liquid $\mathrm{Mg}$ content dictated by the phase diagram, $f_{S}$ needs to increase sharply to reject more $\mathrm{Mg}$ into the interdendritic liquid (because $k<1$ ). Thus, $\mathrm{Mg}$ back diffusion causes $f_{S}$ to increase much faster with decreasing $T$.

Fig. $6 \mathrm{~b}$ shows the microstructure at $2.3 \mathrm{~mm}$ behind the beginning of the quenched $5086 \mathrm{Al}$ mushy zone. As can be expected, at the time of quenching more $\mathrm{Mg}$ back diffusion had occurred here than at the beginning of the quenched mushy zone (Fig. 6a). Unlike the microstructure at the end of the quenched 2014 Al mushy zone (Fig. 4b), no continuous eutectic can be seen. It is unlikely that continuous eutectic exists in 3dimension but appears as isolated eutectic particles in the planar view. This is because, as mentioned previously, heat flow was two-dimensional. So, solidification should also be 2-dimensional (in the plane of the $5086 \mathrm{Al}$ sheet) and any continuous eutectic should thus appear continuous in the planar view. The dark-etching particles in Fig. $6 \mathrm{~b}$ are not eutectic particles that formed from solidification of isolated islands of liquid, either. As will be shown subsequently, these particles were identified by EPMA as intermetallics rich in $\mathrm{Fe}$ and $\mathrm{Mn}$ instead of $\mathrm{Mg}$-rich eutectic $\mathrm{Al}_{3} \mathrm{Mg}_{2}$. Therefore, when quenching took place, little liquid was here in the original mushy zone during welding, i.e., solidification already ended $\left(f_{S} \approx 1\right)$ and dendritic grains already bonded together completely $\left(f_{S} \approx 1\right)$ here in the original mushy zone. Unlike the microstructure at the end of the quenched 
$2014 \mathrm{Al}$ mushy zone (Fig. 4b), no continuous eutectic can be seen. This is because when quenching took place, little liquid was here in the original mushy zone during welding, i.e., solidification already ended $\left(f_{s} \approx 1\right)$ and dendritic grains already bonded together completely $\left(f_{S} \approx 1\right)$ here in the original mushy zone. Since no dendrites can be seen, either, microsegregation was mild. Again, the results suggest significant $\mathrm{Mg}$ back diffusion occurred during solidification. According to the cooling curve (Fig. 3) the temperature at $2.3 \mathrm{~mm}$ behind the beginning of the mushy zone was $560{ }^{\circ} \mathrm{C}$, that is, solidification ended at $560{ }^{\circ} \mathrm{C}$.

Thus, Mg back diffusion caused $f_{S}$ to increase much faster with decreasing $T$, which in turn caused the following three significant changes. First, extensive bridging $\left(f_{S} \approx 1\right)$ occurred earlier. It already occurred at $560{ }^{\circ} \mathrm{C}$, well above $T_{E}=450.5{ }^{\circ} \mathrm{C}$. Second, the freezing temperature range $\Delta T_{f}$ narrowed down from $189.8{ }^{\circ} \mathrm{C}$ (from $T_{L}=640.3{ }^{\circ} \mathrm{C}$ to $T_{E}=$ $450.5{ }^{\circ} \mathrm{C}$ ) to $80.3{ }^{\circ} \mathrm{C}$ (from $T_{L}=640.3{ }^{\circ} \mathrm{C}$ to $T_{E}=560{ }^{\circ} \mathrm{C}$ ). This $\Delta T_{f}$ of $80.3{ }^{\circ} \mathrm{C}$ is even narrower than that of $2014 \mathrm{Al}$, which is $129.8{ }^{\circ} \mathrm{C}$ (from $T_{L}=640.3{ }^{\circ} \mathrm{C}$ to $T_{E}=510.5{ }^{\circ} \mathrm{C}$ ). Third, $\left|d\left(f_{S}\right)^{1 / 2} / d T\right|$ increased, that is, $\left|d T / d\left(f_{S}\right)^{1 / 2}\right|$ and hence the crack susceptibility decrease. All these three changes caused by Mg back diffusion can reduce the crack susceptibility.

Fig. 7 shows the microstructure in the fusion zone of $5086 \mathrm{Al}$ without quenching. The microstructure is very different from that in the fusion zone of $2014 \mathrm{Al}$ without quenching (Fig. 5). No dendrites or continuous eutectic can be seen either at the beginning of the mushy zone or at $2.3 \mathrm{~mm}$ behind it. Thus, the microstructure in Fig. 7 again suggests significant $\mathrm{Mg}$ back diffusion has occurred. The microstructure is consistent with that reported by Cross et al. [14], who showed hardly any eutectic in the 
fusion zone of binary Al-4.0Mg alloy (no quenching). Since this microstructure in Fig. 7 is similar to that in Fig. $6 \mathrm{~b}$, the absence of continuous eutectic and dendritic structure at $2.3 \mathrm{~mm}$ behind the quenched mushy zone (Fig. 6b) was not caused by suppression of eutectic formation from the liquid due to quenching.

Fig. 8 shows the SEM images of the quenched mushy zones of $2014 \mathrm{Al}$ and 5086 Al. Fig. 8a shows the microstructure near the end of the quenched 2014 Al mushy zone, which is similar to the optical micrograph shown in Fig. 4b. However, the light-contrast phase here is now the $\mathrm{Cu}$-rich eutectic and the dark-contrast phase the Al-rich dendrites. To minimize the effect of the surrounding matrix on the EPMA of the light-contrast phase, EPMA was conducted at selected locations where the light-contrast phase is much thicker than average. High $\mathrm{Cu}$ contents were observed, e.g., Al-31.24Cu-3.37Si-2.50Mg$0.25 \mathrm{Mn}-0.12 \mathrm{Fe}$ and $\mathrm{Al}-33.97 \mathrm{Cu}-3.12 \mathrm{Si}-2.87 \mathrm{Mg}-0.10 \mathrm{Mn}-0.07 \mathrm{Fe}$ in wt $\%$. This confirmed the light-contrast phase is the $\mathrm{Cu}$-rich eutectic (close to $\mathrm{Al}-33.2 \mathrm{Cu}$ and containing other elements). Fig. $8 \mathrm{~b}$ shows the microstructure of the quenched $5086 \mathrm{Al}$ mushy zone at 2.3 $\mathrm{mm}$ behind the beginning of the mushy zone. The light-contrast phase in the form of islands correspond to the dark-etching particles shown previously in the optical micrograph in Fig. 6b. EPMA indicated the small isolated islands such as those in Fig. 8b are intermetallic compounds rich in $\mathrm{Fe}$ and $\mathrm{Mn}$, e.g., $\mathrm{Al}-14.74 \mathrm{Fe}-3.79 \mathrm{Mg}-1.41 \mathrm{Mn}$ (in $\mathrm{wt} \%$ ), that form at significantly high temperatures during solidification. Because of the small size of the islands, in EPMA the volume affected by the electron beam (about $2 \mu \mathrm{m}$ diameter) also included the Al-rich matrix and the $\mathrm{Mg}$ in it, which contributed to the 3.79 $\mathrm{wt} \% \mathrm{Mg}$ measured in the small isolated islands. Thus, the small isolated islands are not $\mathrm{Mg}$-rich eutectic $\mathrm{Al}-36.3 \mathrm{Mg}$, that is, essentially no liquid remained at $2.3 \mathrm{~mm}$ behind the 
beginning of the mushy zone at the time of quenching. It is interesting to note that a similar Al-Mg alloy $5182 \mathrm{Al}(\mathrm{Al}-4.74 \mathrm{Mg}-0.34 \mathrm{Mn}-0.28 \mathrm{Fe})$ solidified with very clear particles of $\mathrm{Al}_{6}(\mathrm{FeMn})$, which formed at about $620^{\circ} \mathrm{C}$, but little Mg-rich eutectic [25].

\subsection{Microsegregation}

For simplicity, $2014 \mathrm{Al}(\mathrm{Al} \sim 4.4 \mathrm{Cu}$ ) will be approximated as a binary $\mathrm{Al}-4.4 \mathrm{Cu}$ alloy and $5086 \mathrm{Al}(\mathrm{Al} \sim 4.0 \mathrm{Mg})$ as a binary $\mathrm{Al}-4.0 \mathrm{Mg}$ alloy. For convenience of discussion, the binary $\mathrm{Al}-\mathrm{Cu}$ and $\mathrm{Al}-\mathrm{Mg}$ phase diagrams are shown in Fig. 9 [26]. As shown, the melting point of pure $\mathrm{Al}$ is $T_{m}=660{ }^{\circ} \mathrm{C}$. In the binary $\mathrm{Al}-\mathrm{Cu}$ system the eutectic temperature is $T_{E}=548{ }^{\circ} \mathrm{C}$, the eutectic composition $C_{E}=33.2 \mathrm{wt} \% \mathrm{Cu}$, and the maximum solid solubility $C_{S M}=5.65 \mathrm{wt} \% \mathrm{Cu}$. The maximum freezing temperature range $\Delta T_{f}=T_{m}-T_{E}=112{ }^{\circ} \mathrm{C}$. At $T_{E}$ the equilibrium segregation coefficient $k=0.170(=5.65 /$ 33.2). In the binary Al-Mg system, on the other hand, $T_{E}=450{ }^{\circ} \mathrm{C}, C_{E}=36.3 \mathrm{wt} \% \mathrm{Mg}$, and $C_{S M}=17.5 \mathrm{wt} \% \mathrm{Mg}$. The maximum freezing temperature range $\Delta T_{f}=T_{m}-T_{E}=210$ ${ }^{\circ} \mathrm{C}$. At $T_{E}, k=0.482(=17.5 / 36.3)$. Thus, as compared to the binary $\mathrm{Al}-\mathrm{Cu}$ system, the binary Al-Mg system has a much lower $T_{E}$ and a much higher $C_{S M}, k$ and $\Delta T_{f}$. The much higher $C_{S M}$ means much more $\mathrm{Mg}$ than $\mathrm{Cu}$ can back diffuse from the interdendritic liquid into the Al-rich dendrites during solidification under the same diffusion coefficient and time. An interesting case is the binary Al-Sn alloy system, where Sn has essentially no solubility in solid $\mathrm{Al}\left(C_{S M} \approx 0\right)$. Back diffusion of $\mathrm{Sn}$ into Al-rich dendrites is negligible even given an unlimited diffusion time [15, 27].

Fig. 10 shows the $21 \times 21$ grids superimposed on the images taken with the SEM mode of the EPMA machine just before composition measurements. The microstructure near the end of the quenched $2014 \mathrm{Al}$ mushy zone shown in Fig. 10a is similar to that 
shown previously in Fig. 8a. Likewise, the microstructure at $2.3 \mathrm{~mm}$ behind the beginning of the quenched $5086 \mathrm{Al}$ mushy zone shown in Fig. 10b is similar to that shown previously in Fig. 8b. Composition measurements were conducted at the 441 grid points in each case.

Fig. 11 shows results of composition measurements near the end of the quenched $2014 \mathrm{Al}$ mushy zone. Because of the significant amount of the $\mathrm{Cu}$-rich eutectic present, 71 out of the 441 measured $\mathrm{Cu}$ contents were between $C_{S M}(5.65 \mathrm{wt} \% \mathrm{Cu})$ and $C_{E}(33.2$ wt $\% \mathrm{Cu}$ ), including those close to $C_{E}$ (not shown). These 71 data were disregarded because they do not represent the $\mathrm{Cu}$ contents in the $\mathrm{Al}$-rich phase, which is up to only $C_{S M}$ [21]. They were caused by the fact that the volume of the electron probe $(2 \mu \mathrm{m}$ in diameter below the sample surface) included both the Al-rich phase and the eutectic. The remaining 370 measured $\mathrm{Cu}$ contents were used as the raw data for the Al-rich phase.

Fig. 11a shows the raw data, with the $\mathrm{Cu}$ content plotted against the number that represents the order of composition measurements, with number 1 representing the first measurement and number 370 the last. Fig. 11b shows the normalized data. Here the 370 numbers were rearranged in the order of increasing $\mathrm{Cu}$ content (starting from the number 1 on the left for the lowest $\mathrm{Cu}$ content and number 370 on the right for the highest), divided by 370 and then multiplied by $f_{S E}=0.932$, which is the fraction of the Al-rich solid at $T_{E}$. This $f_{S E}$ value was determined by trial and error until the sum of the area under the curve of the 370 measured $\mathrm{Cu}$ contents plus $C_{E} \times\left(1-f_{S E}\right)$ equals that under the curve (dotted) calculated by the Scheil equation with $C_{o}=4.4 \mathrm{wt} \% \mathrm{Cu}$ [23].

The evidence of $\mathrm{Cu}$ back diffusion near the end of the $2014 \mathrm{Al}$ mushy zone can be seen in Fig. 11b. Up to $f_{S}=0.9$ the measured $\mathrm{Cu}$ content is higher than the calculated one 
based on the Scheil equation. This indicates $\mathrm{Cu}$ back diffusion during solidification. The fraction of the liquid eutectic is $0.088\left(f_{S E}=0.912\right)$ without back diffusion. Since $\mathrm{Cu}$ diffuses from the interdendritic liquid into Al-rich dendrites, less $\mathrm{Cu}$ is left in the liquid near the end of solidification. Consequently, more solid should form to reject more $\mathrm{Cu}$ into the liquid to keep the last liquid at the eutectic temperature at $C_{E}$ as required by the $\mathrm{Al}-\mathrm{Cu}$ phase diagram. Thus, the fraction of the liquid eutectic is less with back diffusion (0.068 because $\left.f_{S E}=0.932\right)$ than without $(0.088)$. (Since all the liquid eutectic solidifies into solid eutectic, the fraction of liquid eutectic is the same as the fraction of solid eutectic or just fraction eutectic.) As mentioned previously, the thinner and less clear eutectic in Fig. 5b than in Fig. 4b indicates $\mathrm{Cu}$ diffusion still occurred after solidification, which suggests $\mathrm{Cu}$ diffusion should be significant at the higher temperatures during solidification.

Fig. 12 shows the results of composition measurements at $2.3 \mathrm{~mm}$ behind the beginning of the quenched $5086 \mathrm{Al}$ mushy zone. Fig. 12a shows the raw data in the order of composition measurements. All 441 measured Mg contents were kept since none were between $C_{S M}$ and $C_{E}$. Fig. 12b shows the normalized data in the order of increasing $\mathrm{Mg}$ content, starting from the lowest $\mathrm{Mg}$ content at $1 / 441$ on the left to $441 / 441$ on the right. Clear evidence of $\mathrm{Mg}$ back diffusion can be seen. First, up to $f_{S}=0.7$, the measured $\mathrm{Mg}$ content is higher than the calculated one based on the Scheil equation with $C_{o}=4.0 \mathrm{wt} \%$ $\mathrm{Mg}$. Second and more importantly, the highest $\mathrm{Mg}$ content measured is $12.3 \mathrm{wt} \% \mathrm{Mg}$, which is well below the maximum $\mathrm{Mg}$ solubility in solid $\mathrm{Al}$, i.e., $C_{S M}=17.5 \mathrm{wt} \% \mathrm{Mg}$. Third, as mentioned previously in Section 3.2, no Mg-rich eutectic Al-36.3Mg was found. As Mg keeps diffusing from the inetrdenfritic liquid into the Al-rich dendrites, the 
liquid is unable to reach $C_{E}=36.3 \mathrm{wt} \% \mathrm{Mg}$ before solidification in $5086 \mathrm{Al}(\sim \mathrm{Al}-$ 4.0Mg) ends. Thus, no Mg-rich eutectic was found in the $5086 \mathrm{Al}$ weld. The binary AlMg phase diagram is such that, without Mg back diffusion, the fraction of the liquid eutectic is only $0.015\left(f_{S E}=0.985\right)$ according to the Scheil equation. Thus, as can be expected, with Mg back diffusion there is no liquid eutectic.

\subsection{Crack susceptibility index}

As shown in Fig. 2a for $2014 \mathrm{Al}$, the length of the quenched mushy zone is $5.78 \mathrm{~mm}$ and the local solidification time $t_{f}$ is $1.36 \mathrm{~s}$. The secondary dendrite-arm spacing $\lambda_{2}$ was measured at about ten different locations near the end of the quenched $2014 \mathrm{Al}$ mushy zone. At these locations, which were close to that of Fig. 4b, secondary dendrite arms were visible. The average value was $8.8 \mu \mathrm{m}$. The diffusion coefficient $D_{S}$ is around $1 \mathrm{x}$ $10^{-12} \mathrm{~m}^{2} / \mathrm{s}$ for $\mathrm{Cu}$ and $\mathrm{Mg}$ in $\mathrm{Al}$ at $600^{\circ} \mathrm{C}$ [28]. Substituting the values of $D_{S}, t_{f}$ and $\lambda_{2}$ into Eq. (3) and then Eq. (2), $\alpha^{\prime}=0.070$. As will be seen subsequently, crack susceptibility curves for Al-Cu alloys are shown at $\alpha^{\prime}=0,0.025,0.050$ and 0.075. Thus, in Fig. 13 the $T-\left(f_{S}\right)^{1 / 2}$ curves for Al-Cu alloys calculated using Eq. (1) are shown for $\alpha^{\prime}=0.075$ as well as $\alpha^{\prime}=0 . \lambda_{2}$ near the end of the quenched mushy zone of $5086 \mathrm{Al}$ could not be found as no discernible dendrites existed (Fig. 6b). However, in the mushy zone of $5086 \mathrm{Al}$ where the dendritic structure was still visible, the measured $\lambda_{2}$ was close to that of $2014 \mathrm{Al}$ at the same distance from the pool boundary. Thus, for the purpose of comparison with $2014 \mathrm{Al}$, curves of $T$ vs. $\left(f_{S}\right)^{1 / 2}$ for Al-Mg alloys are shown in Fig. 14 for $\alpha^{\prime}=0$ and 0.075 .

During terminal solidification there is a point very close to $f_{S}=1$ at which dendritic grains will have to bond together extensively, that is, extensive bridging has to occur. 
Here, the crack susceptibility ends because there is no longer enough liquid left to form continuous liquid films to separate grains. This point will be called $f_{S B}$, with the subscript "B" denoting bridging. It has been shown that $\left(f_{S B}\right)^{1 / 2}=0.99$ works well for $\mathrm{Al}$ alloys [9, 17]. A notable exception is Al-Sn alloys, where $\left(f_{S B}\right)^{1 / 2}=0.995$ works better in view of the very thin continuous liquid films between grains (very low dihedral angle) [17]. In the RDG model [4] the crack susceptibility was assumed to end at $f_{S}=0.98$, that is, at $\left(f_{S}\right)^{1 / 2}=$ 0.99 , which is identical to assuming $\left(f_{S B}\right)^{1 / 2}=0.99$.

In Figs. 13 and 14, the vertical dotted line indicates extensive bridging at $\left(f_{S B}\right)^{1 / 2}=$ 0.99 , beyond which the steepness of the curves of $T$ vs. $\left(f_{S}\right)^{1 / 2}$ is no longer relevant. The short straight lines in blue color are tangents to the $T-\left(f_{S}\right)^{1 / 2}$ curves at the locations of maximum steepness $\left|d T / d\left(f_{S}\right)^{1 / 2}\right|$ before $\left(f_{S B}\right)^{1 / 2}=0.99$. As can be seen by comparing Figs. 13 and 14, the Al-Mg alloys have much higher maximum steepness than the $\mathrm{Al}-\mathrm{Cu}$ alloys. This is because Al-Mg alloys have a much wider freezing temperature range (much lower $T_{E}$ ) and much less eutectic liquid at the same solute contents.

Back diffusion causes the maximum steepness $\left|d T / d\left(f_{S}\right)^{1 / 2}\right|$, that is, the crack susceptibility index to decrease. As can be seen in Figs. 13 and 14, increasing $\alpha^{\prime}$ from 0 to 0.075 , causes the maximum steepness $\left|d T / d\left(f_{S}\right)^{1 / 2}\right|$ to decrease. In the case of binary $\mathrm{Al}-\mathrm{Cu}$ alloys, as shown in Fig. 13, the decrease is very clear for $\mathrm{Al}-0.5 \mathrm{Cu}$ but very slight for $\mathrm{Al}-7 \mathrm{Cu}$. Without back diffusion $\left(\alpha^{\prime}=0\right) \mathrm{Al}-7 \mathrm{Cu}$ has the lowest fraction of solid at the eutectic temperature $f_{S E}$, i.e., $\left(f_{S E}\right)^{1 / 2}=0.92$ or $f_{S E}=0.85$. In other word, the fraction of liquid eutectic is highest for $\mathrm{Al}-7 \mathrm{Cu}$, i.e., $f_{E}=0.15(=1-0.85)$. (Note that the fraction of liquid eutectic is the same as the fraction of solid eutectic since all liquid eutectic solidifies as solid eutectic.) Among all Al-Cu alloys the effect of back diffusion on 
decreasing the maximum steepness $\left|d T / d\left(f_{S}\right)^{1 / 2}\right|$ seems most significant for those with 0.5 to $2 \mathrm{wt} \% \mathrm{Cu}$. As can be seen in Fig. 13a, for these alloys $\left(f_{S E}\right)^{1 / 2}>0.98$ or $f_{S E}>0.96$, that is, $f_{E}<0.04(=1-0.96)$. Therefore, with back diffusion to increase $f_{S}$ significantly faster with decreasing $T$, this small $f_{E}$ can become zero before $T_{E}$ is reached and the maximum steepness $\left|d T / d\left(f_{S}\right)^{1 / 2}\right|$ can be reduced significantly. Likewise, Fig. 14 shows that when $\alpha^{\prime}$ is increased from 0 to 0.075 , the maximum steepness $\left|d T / d\left(f_{S}\right)^{1 / 2}\right|$ of Al$2 \mathrm{Mg}$ is greatly reduced but not $\mathrm{Al}-14 \mathrm{Mg}$. Among all $\mathrm{Al}-\mathrm{Mg}$ alloys the effect of back diffusion on decreasing the maximum steepness $\left|d T / d\left(f_{S}\right)^{1 / 2}\right|$ seems most significant for those with 2 to $7 \mathrm{wt} \% \mathrm{Mg}$. Again, for these alloys $\left(f_{S E}\right)^{1 / 2}>0.98$ or $f_{S E}>0.96$ and $f_{E}<$ 0.04. Thus, it can be seen in Fig. 13 and 14 that the alloys affected most by back diffusion are those already having a small $f_{E}(<$ about 0.04$)$ when back diffusion is still absent. Consequently, with back diffusion to increase $f_{S}$ significantly faster with decreasing $T$, the small $f_{E}$ can decrease to nearly zero and the maximum steepness $\left|d T / d\left(f_{S}\right)^{1 / 2}\right|$, i.e., the crack susceptibility of these alloys, can be reduced significantly.

Fig. 15 shows the calculated crack susceptibility curves of $\mathrm{Al}-\mathrm{Cu}$ and $\mathrm{Al}-\mathrm{Mg}$ alloys. The crack susceptibility index, that is, the maximum steepness $\left|d T / d\left(f_{S}\right)^{1 / 2}\right|$, is plotted as a function of the solute content $C_{o}$ at various levels of the diffusion parameter $\alpha$. As shown, with increasing back diffusion, that is, increasing $\alpha$, the peak crack susceptibility drops and shifts to higher solute contents. The drop in the peak crack susceptibility is much more significant for Al-Mg alloys than for Al-Cu alloys. This is because, $f_{S}$ vs. $T$ and hence $\left|d T / d\left(f_{S}\right)^{1 / 2}\right|$ is affected not by $\alpha^{\prime}$ alone but by $k \alpha^{\prime}$ as can be seen in Eq. (1). As mentioned previously, the partition coefficient of $\mathrm{Al}-\mathrm{Mg}\left(k=0.482\right.$ at $\left.T_{E}\right)$ is much higher than that of Al-Cu $\left(k=0.170\right.$ at $\left.T_{E}\right)$. This much higher $k$ at $T_{E}$ is associated with 
the much higher $C_{S M}$ of $\mathrm{Mg}(17.5 \mathrm{wt} \% \mathrm{Mg})$ than that of $\mathrm{Cu}(5.65 \mathrm{wt} \% \mathrm{Cu})$. Thus, at the same value of $\alpha^{\prime}$, the drop in the peak crack susceptibility is much more significant for $\mathrm{Al}-\mathrm{Mg}$ alloys than for $\mathrm{Al}-\mathrm{Cu}$ alloys.

The effect of back diffusion on the crack susceptibility of 2014 Al can be seen in Fig. 15a. The crack susceptibility of Al-4.4Cu ( $2014 \mathrm{Al})$ remains essentially unchanged at $2000{ }^{\circ} \mathrm{C}$ when the diffusion parameter is increased from $\alpha^{\prime}=0$ to 0.075 . The crack susceptibility is expressed in ${ }^{\circ} \mathrm{C}$ because the crack susceptibility index is the maximum steepness $\left|d T / d\left(f_{S}\right)^{1 / 2}\right|$, which has the unit of ${ }^{\circ} \mathrm{C}$. As mentioned previously, the maximum steepness $\left|d T / d\left(f_{S}\right)^{1 / 2}\right|$ is most affected by back diffusion in Al-Cu alloys with 0.5 to $2 \mathrm{wt} \% \mathrm{Cu}$, which does not include $\mathrm{Al}-4.4 \mathrm{Cu}$. However, as shown in Fig. 15b, increasing the diffusion parameter from $\alpha^{\prime}=0$ to 0.075 causes the crack susceptibility of $\mathrm{Al}-4.0 \mathrm{Mg}(\sim 5086 \mathrm{Al})$ to drop sharply from 9000 to $1000{ }^{\circ} \mathrm{C}$, which is lower than the $2000{ }^{\circ} \mathrm{C}$ crack susceptibility index of $2014 \mathrm{Al}$. Thus, with back diffusion $5086 \mathrm{Al}$ can be less crack susceptible than 2014 Al. As mentioned previously, the maximum steepness $\left|d T / d\left(f_{S}\right)^{1 / 2}\right|$ is most affected by back diffusion in Al-Mg alloys with 2 to $7 \mathrm{wt} \% \mathrm{Mg}$, which includes Al-4.0Mg. This makes 5086 Al less crack susceptible than 2014 Al, consistent with the better weldability of 5086 Al than 2014 Al despite the much wider freezing temperature range of $5086 \mathrm{Al}$.

According to Fig. 14b, the interdendritic liquid in Al-4.0Mg ( $5086 \mathrm{Al})$ disappears at $560^{\circ} \mathrm{C}$. Because of significant $\mathrm{Mg}$ back diffusion, solidification of liquid $\mathrm{Al}-4.0 \mathrm{Mg}$ does not end at the eutectic temperature $450{ }^{\circ} \mathrm{C}$ but earlier at a much higher temperature $560{ }^{\circ} \mathrm{C}$. This temperature was used previously in Fig. 3a to determine the $2.30 \mathrm{~mm}$ length of the $5086 \mathrm{Al}$ mushy zone. 
Thus, the index for the susceptibility to solidification cracking $[5,9]$ and effect of back diffusion on the crack susceptibility $[17,27,29]$ proposed recently are both consistent with the microstructure and microsegregation in the quenched mushy zone in the present study.

\section{Conclusions}

1. An experimental technique was developed to help understand solidification cracking by quenching the mushy zone with molten Woods metal and measuring the cooling curve during welding.

2. The quenched $2014 \mathrm{Al}$ mushy zone indicates solidification in the original mushy zone ended at $T_{E}$ and dendritic grains were still separated by thin liquid films near $T_{E}$ to allow intergranular cracking to occur.

3. The quenched 5086 Al mushy zone indicates significant $\mathrm{Mg}$ back diffusion occurred in the original mushy zone (because of the very high $C_{S M}$ of $17.5 \mathrm{wt} \%$ $\mathrm{Mg}$ ), causing: 1. $f_{S}$ to increase much faster with decreasing $T, 2 . \Delta T_{f}$ to narrow down (narrower than that in $2014 \mathrm{Al}$ ) by ending solidification early (well above $T_{E}$ ), and 3. dendritic grains to bond together extensively to resist intergranular cracking early (well above $\left.T_{E}\right)$. Since $\left|d\left(f_{S}\right) / d T\right|$ increased, $\left|d T / d\left(f_{S}\right)^{1 / 2}\right|$ decreased to decrease the crack susceptibility index, i.e., the maximum $\left|d T / d\left(f_{S}\right)^{1 / 2}\right|$. All these changes caused by Mg back diffusion reduce the crack susceptibility.

4. Calculated $T-\left(f_{S}\right)^{1 / 2}$ curves also showed that the maximum $\left|d T / d\left(f_{S}\right)^{1 / 2}\right|$ is reduced significantly by back diffusion in $\mathrm{Al}-4.0 \mathrm{Mg}(\sim 5086 \mathrm{Al})$ but not $\mathrm{Al}-4.4 \mathrm{Cu}(\sim 2014$ $\mathrm{Al})$. 
5. The present study explains why Al-Mg alloys, despite their much wider nominal $\Delta T_{f}$, i.e., $\left(T_{L}-T_{E}\right)$, can still be less susceptible to solidification cracking than Al$\mathrm{Cu}$ alloys.

6. The occurrence of cracking during quenching $2014 \mathrm{Al}$ but not $5086 \mathrm{Al}$ is consistent with the lower crack susceptibility of $5086 \mathrm{Al}$ despite its much wider nominal $\Delta T_{f}$, i.e., $\left(T_{L}-T_{E}\right)$.

7. The present study verified that the maximum $\left|d T / d\left(f_{S}\right)^{1 / 2}\right|$ can be used as an index to predict both the crack susceptibility [9] and the effect of back diffusion during solidification on the crack susceptibility [17, 27, 29].

\section{Acknowledgements}

This work was supported by the National Science Foundation under Grant No. DMR 1500367. The coauthor Liu was supported by the China Scholarship Council as a visiting graduate student at the University of Wisconsin-Madison. The authors would like to thank Dr. John H. Fournelle of the Department of Geoscience, UW-Madison for conducting composition measurements by EPMA. They would also like to thank Dr. Ping Yu for many helpful discussions on both the weld microstructure and EPMA and Mr. Tayfun Soysal for taking SEM images.

\section{References}

[1] S. Kou, Welding Metallurgy, second ed., John Wiley and Sons, Hoboken, 2013, 257-300.

[2] M.C. Flemings, Solidification Processing, McGraw-Hill, New York, 1974 (252-6, Appendix). 
[3] J. Campbell, Castings, second ed., Butterworth Heinemann, Oxford, 2003, 216247.

[4] M. Rappaz, J.M. Drezet, M. Gremaud, A new hot-tearing criterion, Metall. Mater. Trans. 30A (1999) 449-455.

[5] S. Kou, A criterion for cracking during solidification, Acta Mater. 88 (2015) 366374.

[6] J. Campbell, private communications, United Kingdom, June 2014.

[7] N. Coniglio and C. E. Cross, Mechanisms for solidification cracking initiation and growth in aluminum welding, Metall. Mater. Trans. A 40A (2009) 2718-2728.

[8] S. Kou, Transport Phenomena and Materials Processing, John Wiley and Sons, Hoboken, 1996, 64-67.

[9] S. Kou, A simple index for predicting the susceptibility to solidification cracking in welding, Welding Journal, 94 (2015) 374-s to 388-s.

[10] Pandat - Phase Diagram Calculation software package for Multicomponent Systems, Computherm LLC, Madison, WI 53719, 2001.

[11] PanAluminium - Thermodynamic database for Commercial Aluminum Alloys, Computherm LLC, Madison, WI 53719, 2001.

[12] G.H. Gulliver, Metallic Alloys (Appendix), Charles Griffin \& Co., Ltd., London, 1922.

[13] E. Scheil, Bemerkungen zur Schlichtkristallbildung, Z. Metallk., 34 (1942) 70.

[14] C.E. Cross, D.L. Olson, Hot tearing model to assess aluminum weldability, in Aluminum Alloys Their Physical and Mechanical Properties, vol. III, Conference Proceedings, Charlotsville, VA, 1986, pp. 1869-1875. 
[15] R.A. Rosenberg, M.C. Flemings, H.F. Taylor, Nonferrous binary alloys hot tearing, Trans. American Foundry Society, 68(1960) 518-528.

[16] W. Kurz and D.J. Fisher, Fundamentals of Solidification, 4th ed., Trans Tech Publications, Aedermannsdorf, Switzerland, 1998, pp. 234-235.

[17] J. Liu and S. Kou, Effect of diffusion on susceptibility to cracking during solidification, Acta Materialia, 100 (2015) 359-368.

[18] S. Kou and Y. Le, Nucleation Mechanisms and Grain Refining of Weld Metal, Weld. J., 1986, 65, 305s-313s.

[19] T. Yuan, S. Kou and Z. Luo, Grain Refining by Ultrasonic Stirring of the Weld Pool, Acta Materialia, 106 (2016) 144-154.

[20] T. Yuan, S. Kou and Z. Luo, Grain Refining of Magnesium Welds by Arc Oscillation, Acta Materialia, 116 (2016) 166-176.

[21] S. Kou and Y. Le, The Effect of Quenching on the Solidification Structure and Transformation Behavior of Stainless Steel Welds, Metallurgical Transactions A, 13A (1982) 1141.

[22] Low-Melting Point 158F Alloy Ingot, Roto Metals, San Leandro, CA. www.rotometals.com.

[23] M.N. Gungor, A statistically significant experimental technique for investigating microsegregation in cast alloys, Metallurgical Transactions A, 20A (1989) 2529-2533.

[24] F.-Y. Xie, T. Kraft, Y. Zuo, C.-H. Moon and Y. A. Chang, Microstructure and microsegregation in Al-rich Al-Cu-Mg alloys, Acta Materialia 47 (1999) 4895000. 
[25] L. Backerud, E. Krol and J. Tamminen, Solidification Characteristics of Aluminum Alloys, Volume 1: Wrought Alloys, Akan Aluminium, Universitetsforlaget AS, Oslo, p.119-123.

[26] American Society for Metals. 1986. Binary Alloy Phase Diagrams vol. 1: Metals Park, O.H., American Society for Metals, p. 106 and p. 130.

[27] J. Liu and S. Kou: "Crack Susceptibility of Binary Aluminum Alloys during Solidification”, Acta Materialia, vol. 110, 2016, pp. 84-94.

[28] D.R. Poirier, G.H. Geiger, Transport Phenomena in Materials Processing, TMS Publications, Warrendale PA, 1994, p. 432.

[29] J. Liu and S. Kou, Crack Susceptibility of Binary Aluminum Alloys: Analytical Equations, in the Proceedings of Shape Casting: 6th International Symposium, Edited by: Murat Tiryakiog $`$ lu, Mark Jolly, and Glenn Byczynski, TMS (The Minerals, Metals \& Materials Society), 2016, 11-18.

Table 1 Compositions of workpiece in wt $\%$.

\begin{tabular}{|l|l|l|l|l|l|l|l|}
\hline & $\mathrm{Cu}$ & $\mathrm{Mg}$ & $\mathrm{Si}$ & $\mathrm{Mn}$ & $\mathrm{Cr}$ & $\mathrm{Fe}$ & $\mathrm{Al}$ \\
\hline $2014 \mathrm{Al}$ & 4.40 & 0.56 & 0.83 & 0.77 & 0.01 & 0.26 & balance \\
\hline $5086 \mathrm{Al}$ & 0.04 & 4.00 & 0.22 & 0.26 & 0.11 & 0.35 & balance \\
\hline
\end{tabular}




\section{Figure captions}

Fig. 1 Quenching and measuring cooling curve during arc welding: (a) weld pool and the mushy zone behind it (top view); (b) plunging thermocouple into weld pool (vertical section); (c) pouring molten Woods metal to quench mushy zone shortly after plunging thermocouple (vertical section). $T_{L}$ : liquidus temperature; $T_{E}$ : eutectic temperature.

Fig. 2 Results of quenching 2014 Al weld: (a) cooing curve; (b) top surface; (c) bottom surface. Cracking extends across nearly entire centerline of mushy zone. Quenching took place at $4 \mathrm{~s}$.

Fig. 3 Results of quenching 5086 Al weld: (a) cooing curve; (b) top surface; (c) bottom surface. No cracking is visible. Quenching took place at 4.9 s. The $5086 \mathrm{Al}$ weld with thermal measurement was unintentionally cut before photographing. Microstructural analysis indicates solidification ends at $560{ }^{\circ} \mathrm{C}$ as will be explained subsequently.

Fig. 42014 Al weld quenched: (a) micrograph near quenched pool boundary; (b) micrograph at $5.78 \mathrm{~mm}$ behind quenched pool boundary. Broken white line indicates quenched pool bounary.

Fig. 52014 Al weld not quenched: (a) micrograph near crater boundary; (b) $5.78 \mathrm{~mm}$ behind crater boundary.

Fig. 65086 Al weld quenched: (a) micrograph near quenched pool boundary (dendritic structure not as clear as in Fig. 4a); (b) micrograph at $2.3 \mathrm{~mm}$ behind quenched pool boundary (no dendrites or continuous eutectic as those in Fig. 4b). Much less eutectic is visible here than in quenched $2014 \mathrm{Al}$ (Fig. 4). 
Fig. $75086 \mathrm{Al}$ weld not quenched: (a) micrograph near crater boundary; (b) micrograph at $2.3 \mathrm{~mm}$ behind crater boundary. No dendrites or continuous eutectic as those in Fig. 5.

Fig. 8 SEM images of quenched welds: (a) $2014 \mathrm{Al}$ at $5.78 \mathrm{~mm}$ behind quenched pool boundary; (b) $5086 \mathrm{Al}$ at $2.3 \mathrm{~mm}$ behind quenched pool boundary. GBs: grain boundaries.

Fig. 9 Binary phase diagrams of $\mathrm{Al}$ alloys: (a) $\mathrm{Al}-\mathrm{Cu}$; (b) $\mathrm{Al}-\mathrm{Mg}$ [26]. $2014 \mathrm{Al}$ alloy is essentially $\mathrm{Al}-4.4 \mathrm{Cu}$ and $5086 \mathrm{Al}$ alloy $\mathrm{Al}-4.0 \mathrm{Mg}$ by wt\%.

Fig. 10 Grids for composition measurements by EPMA: (a) $2014 \mathrm{Al}$ at $5.78 \mathrm{~mm}$ behind quenced pool boundary; (b) $5086 \mathrm{Al}$ at $2.3 \mathrm{~mm}$ behind quenched pool boundary.

Fig. $11 \mathrm{Cu}$ microsegregation near end of quenched $2014 \mathrm{Al}(\sim \mathrm{Al}-4.4 \mathrm{Cu})$ mushy zone measured by EPMA: (a) raw data; (b) normalized data. Eutectic is still present.

Fig. $12 \mathrm{Mg}$ microsegregation near end of quenched $5086 \mathrm{Al}(\sim \mathrm{Al}-4.0 \mathrm{Mg})$ mushy zone measured by EPMA: (a) raw data; (b) normalized data. Highest $\mathrm{Mg}$ content measured (12.3 wt\%) is well below $C_{S M}$ and eutectic disappears, indicating significant $\mathrm{Mg}$ back diffusion.

Fig. $13 T-\left(f_{S}\right)^{1 / 2}$ curves of binary Al-Cu alloys: (a) without diffusion; (b) with diffusion. Extensive bridging is assumed to occur at $\left(f_{S}\right)^{1 / 2}=0.99$ to end crack susceptibility, before which the maximum steepness of alloys with 0.5 to $2 \mathrm{wt} \% \mathrm{Cu}$ is most affected by back diffusion.

Fig. $14 T-\left(f_{S}\right)^{1 / 2}$ curves of binary Al-Mg alloys: (a) without diffusion; (b) with back diffusion. The maximum steepness of alloys with 2 to $7 \mathrm{wt} \% \mathrm{Mg}$ is most affected by 
back diffusion. Dotted horizontal line indicates interdendritic liquid in $\mathrm{Al}-4.0 \mathrm{Mg}$ disappears at $560^{\circ} \mathrm{C}$, which is shown in Fig. 3a.

Fig. 15 Effect of back diffusion on crack susceptibility: (a) Al-Cu alloys (alloys with 0.5 to $2 \mathrm{wt} \% \mathrm{Cu}$ most affected); (b) Al-Mg alloys (alloys with 2 to $7 \mathrm{wt} \% \mathrm{Mg}$ most affected). At $\alpha^{\prime}=0.075$ back diffusion causes crack susceptibility of Al-4.0Mg ( $5086 \mathrm{Al})$ to drop from 9000 to $1000{ }^{\circ} \mathrm{C}$ but hardly changes that of $\mathrm{Al}-4.4 \mathrm{Cu}(\sim 2014$ $\mathrm{Al})$. 


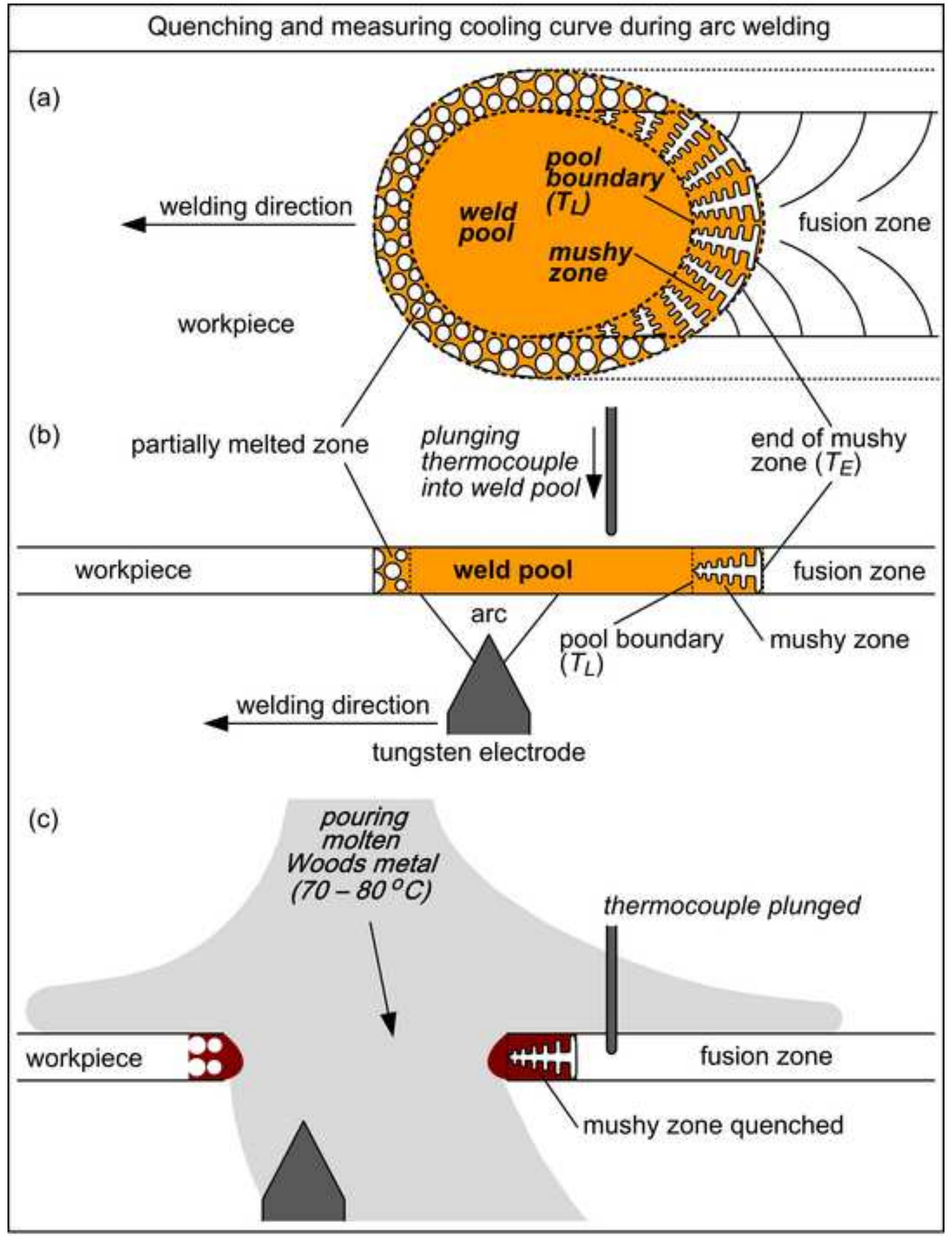




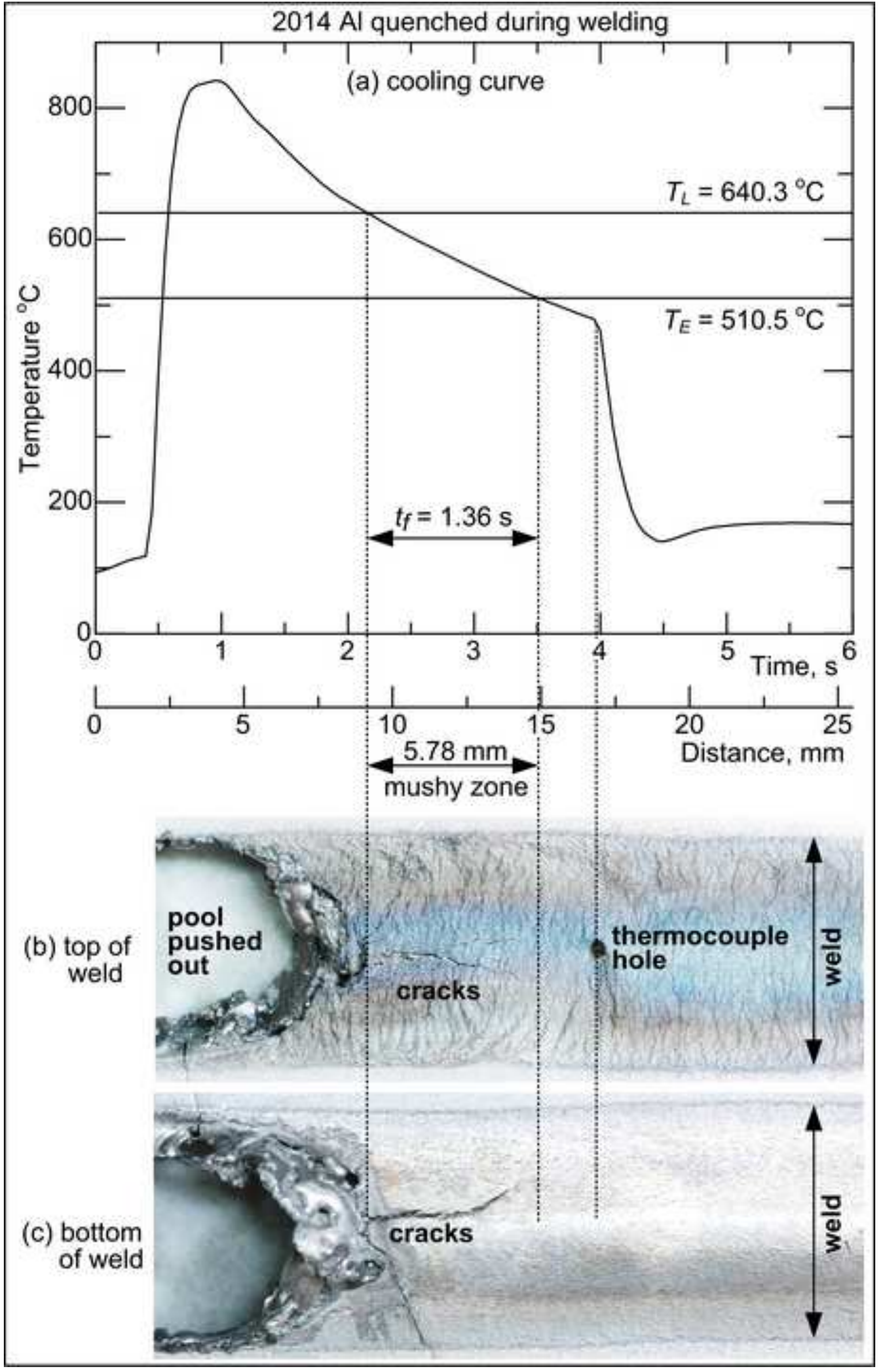




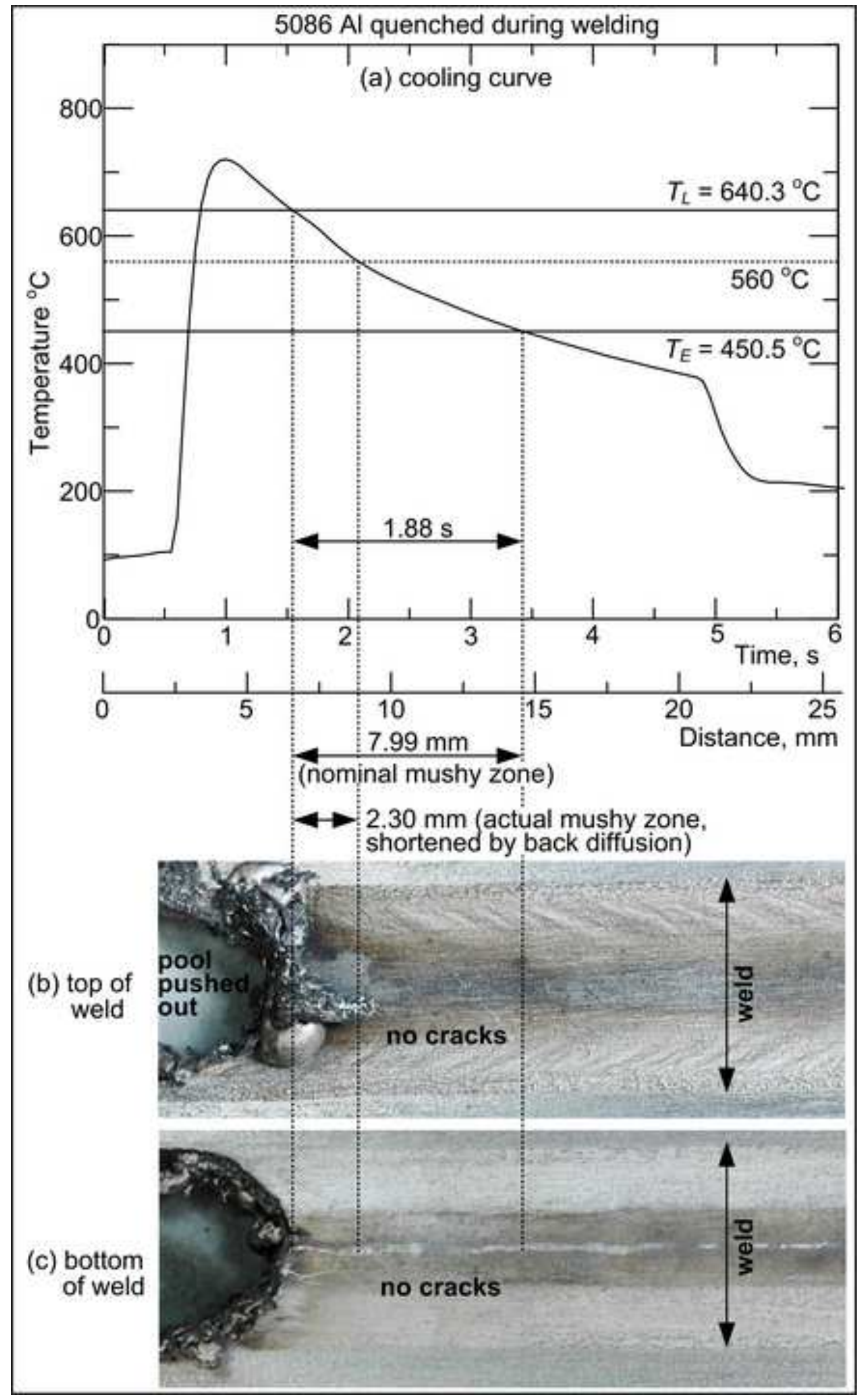




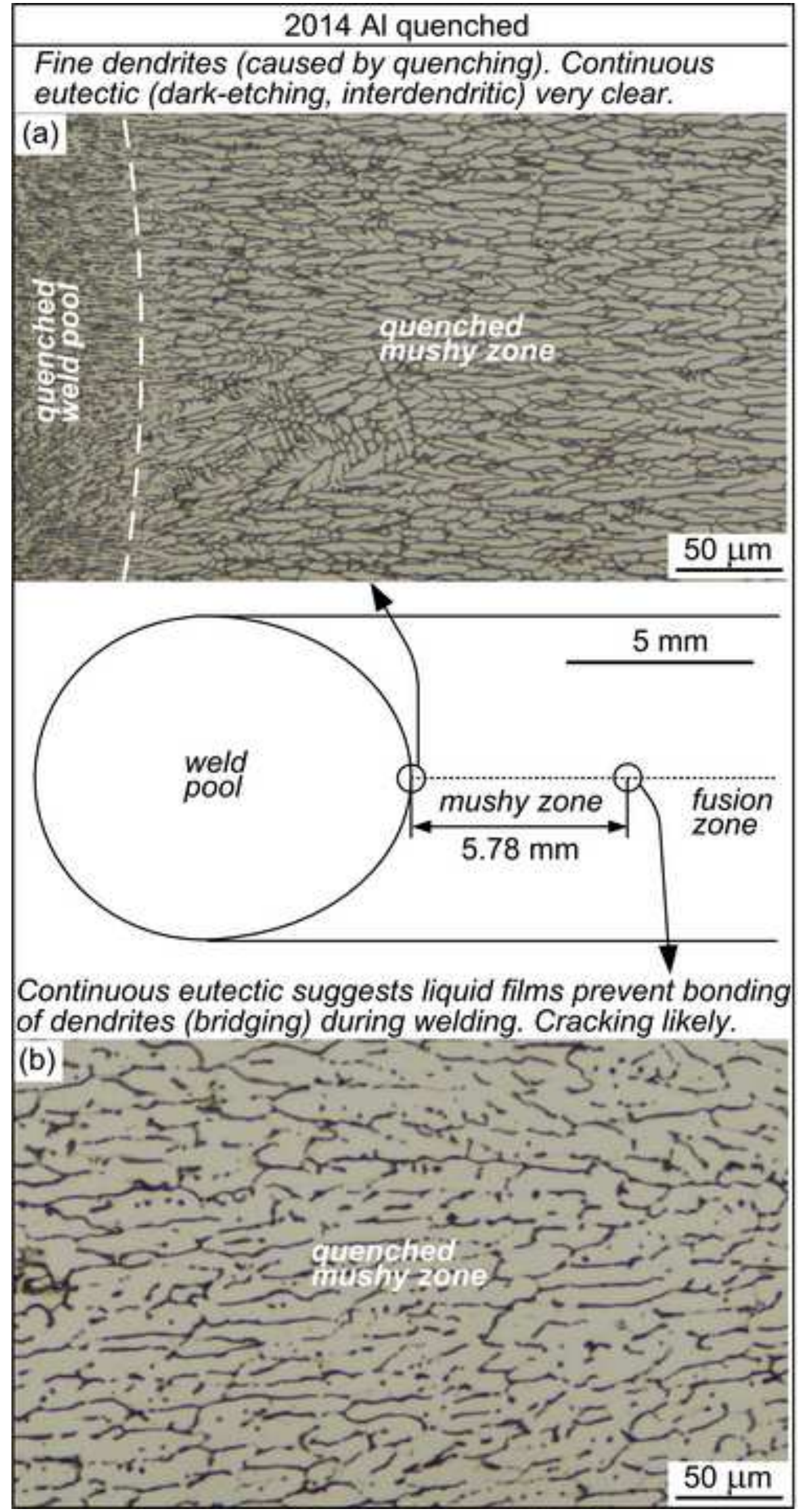




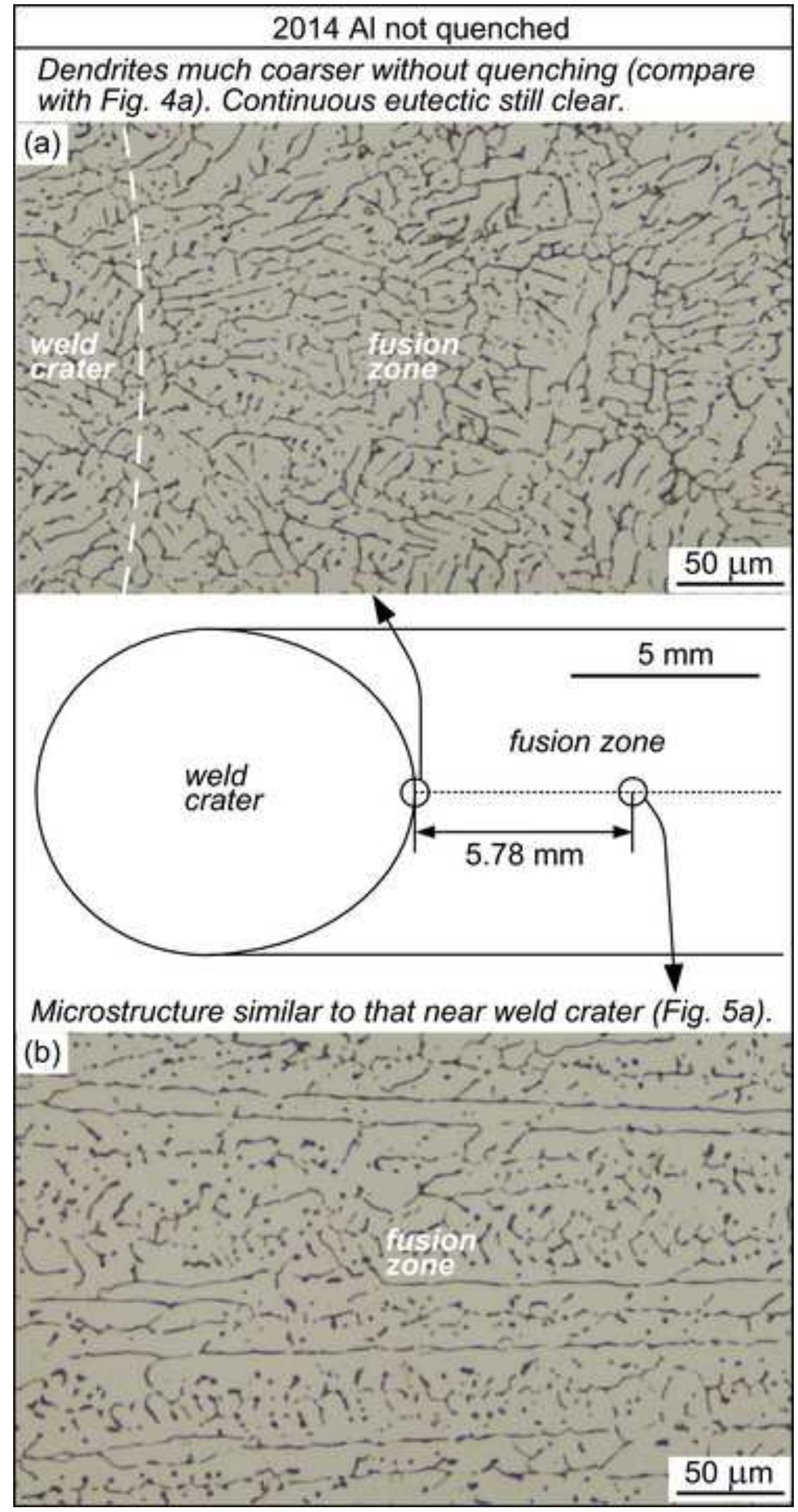




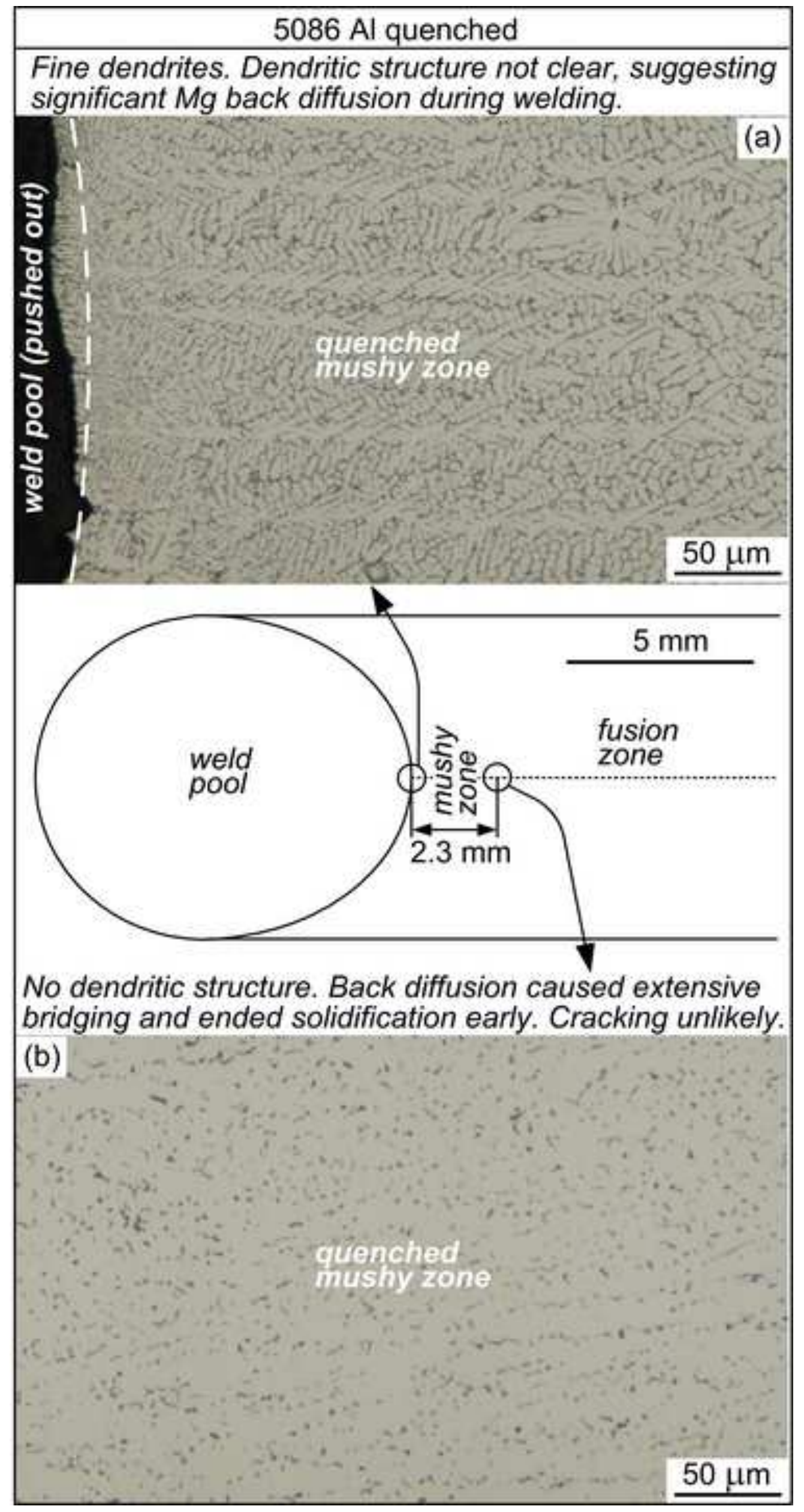




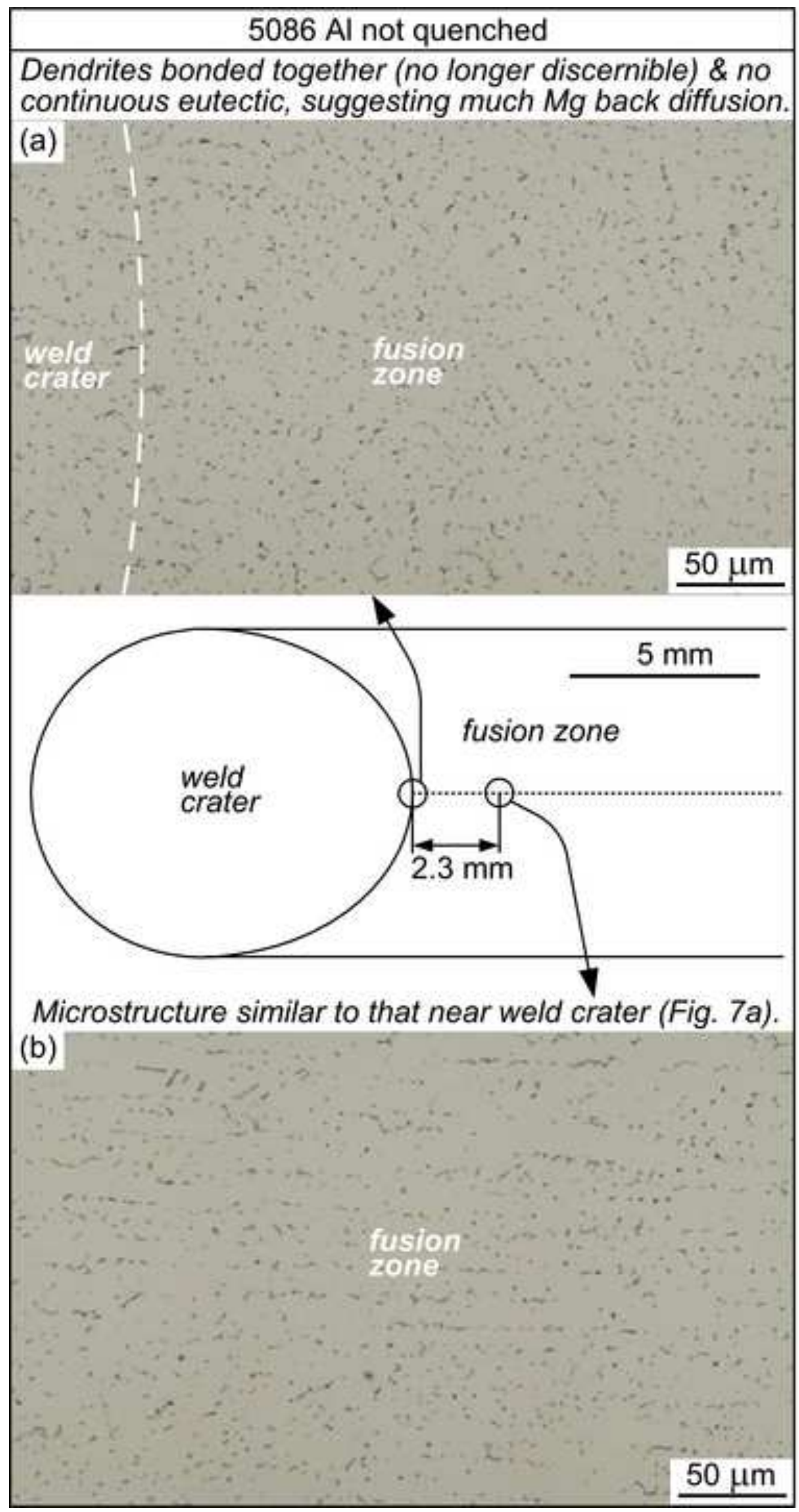




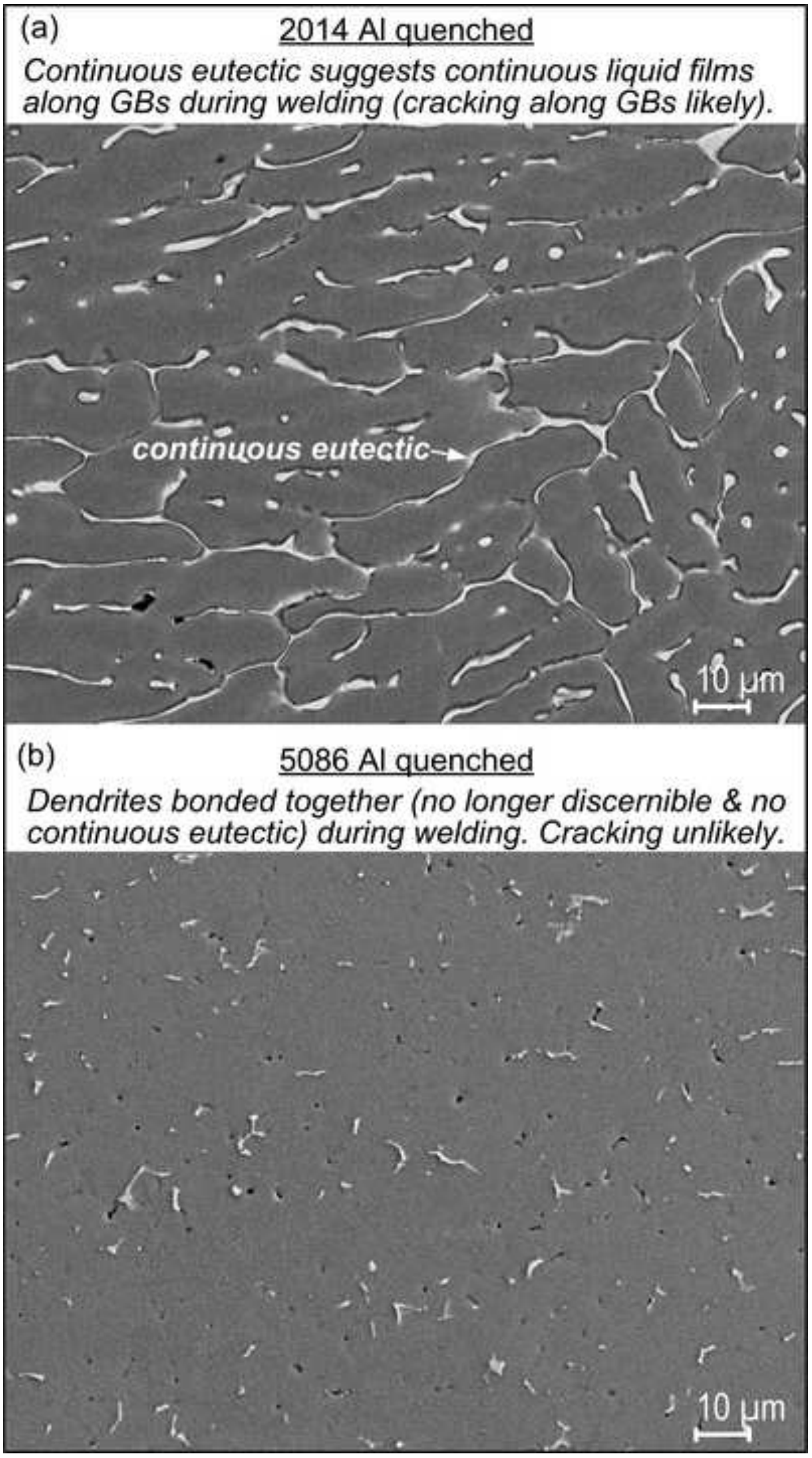




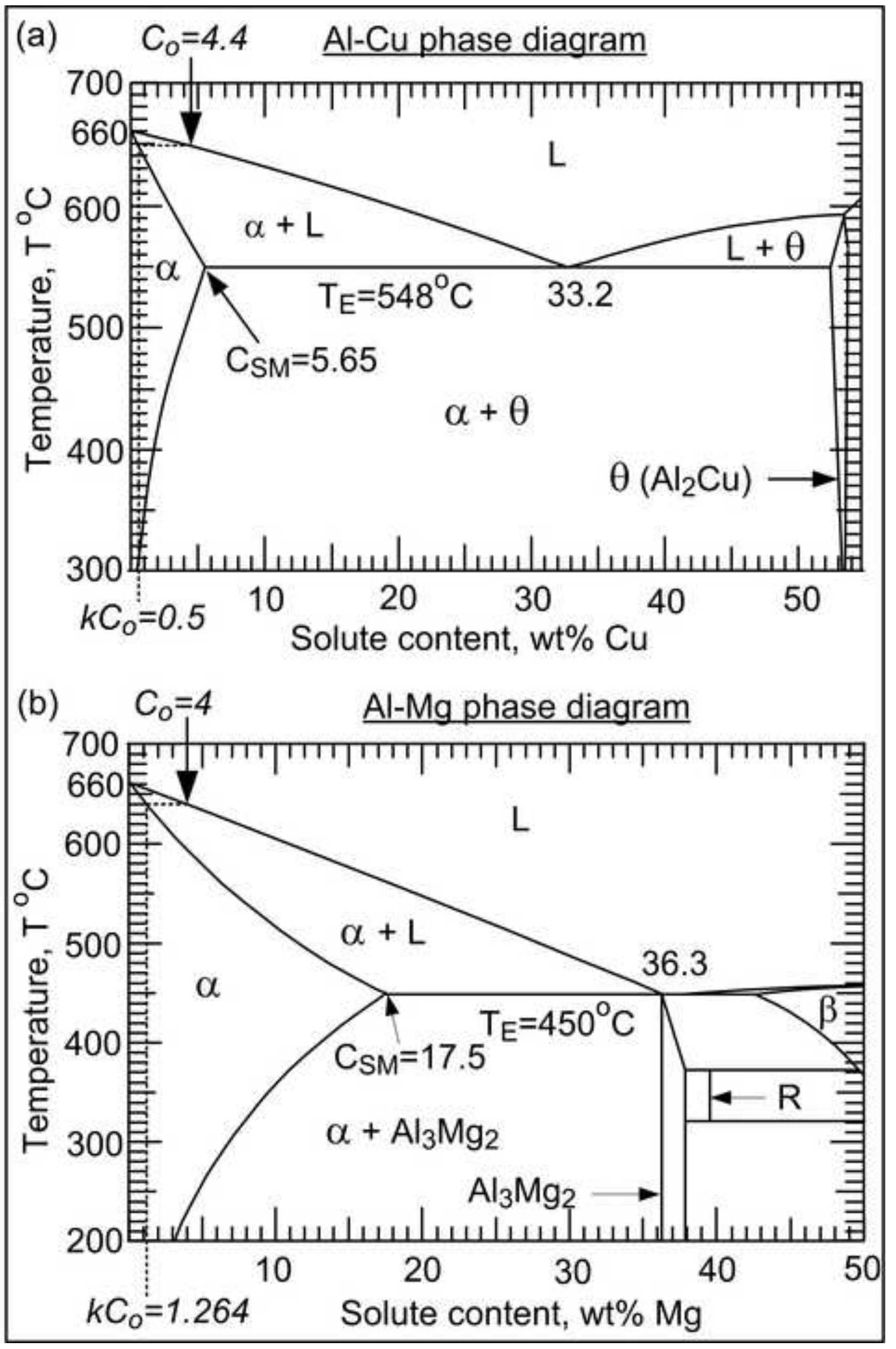




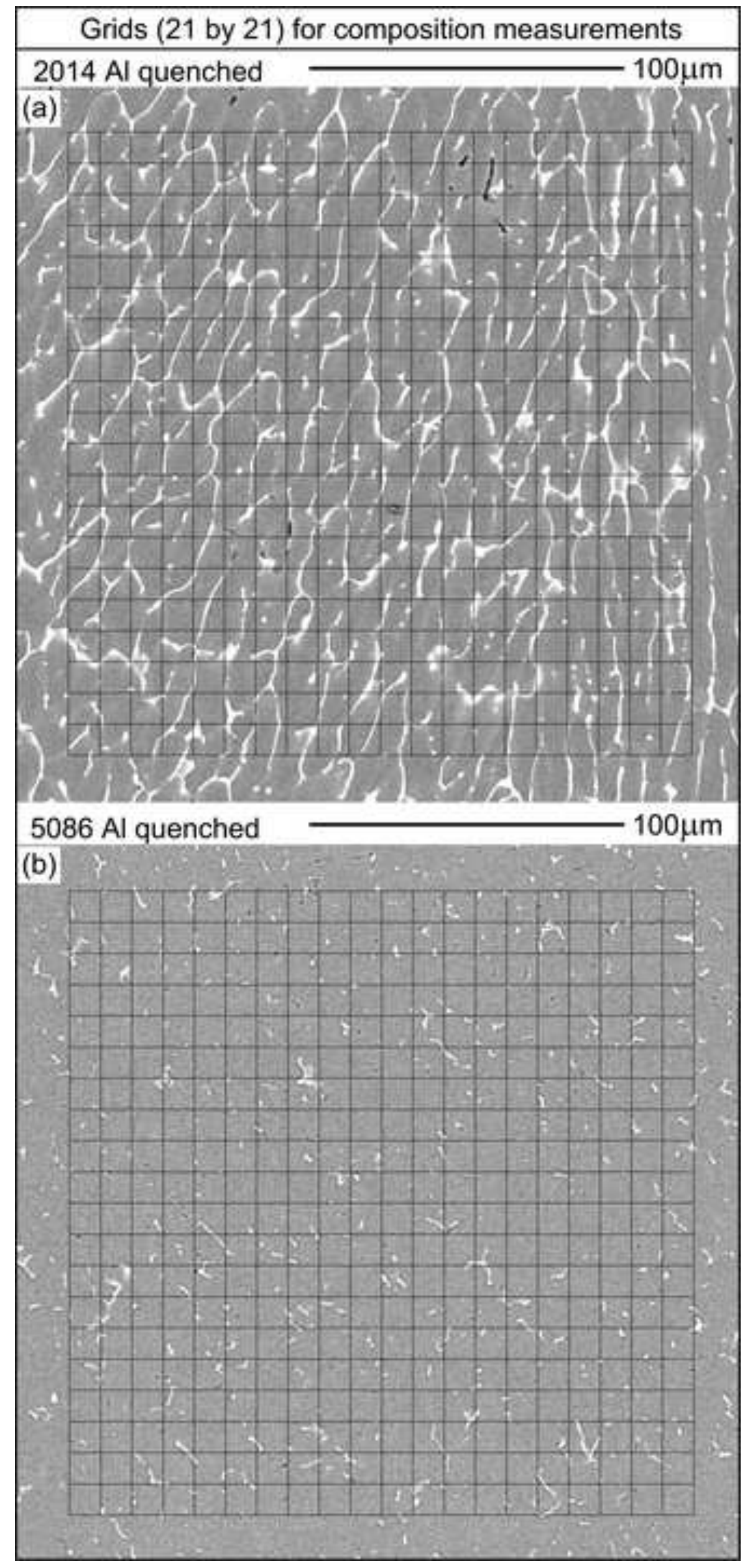


2014 Al: back diffusion evident but eutectic still present
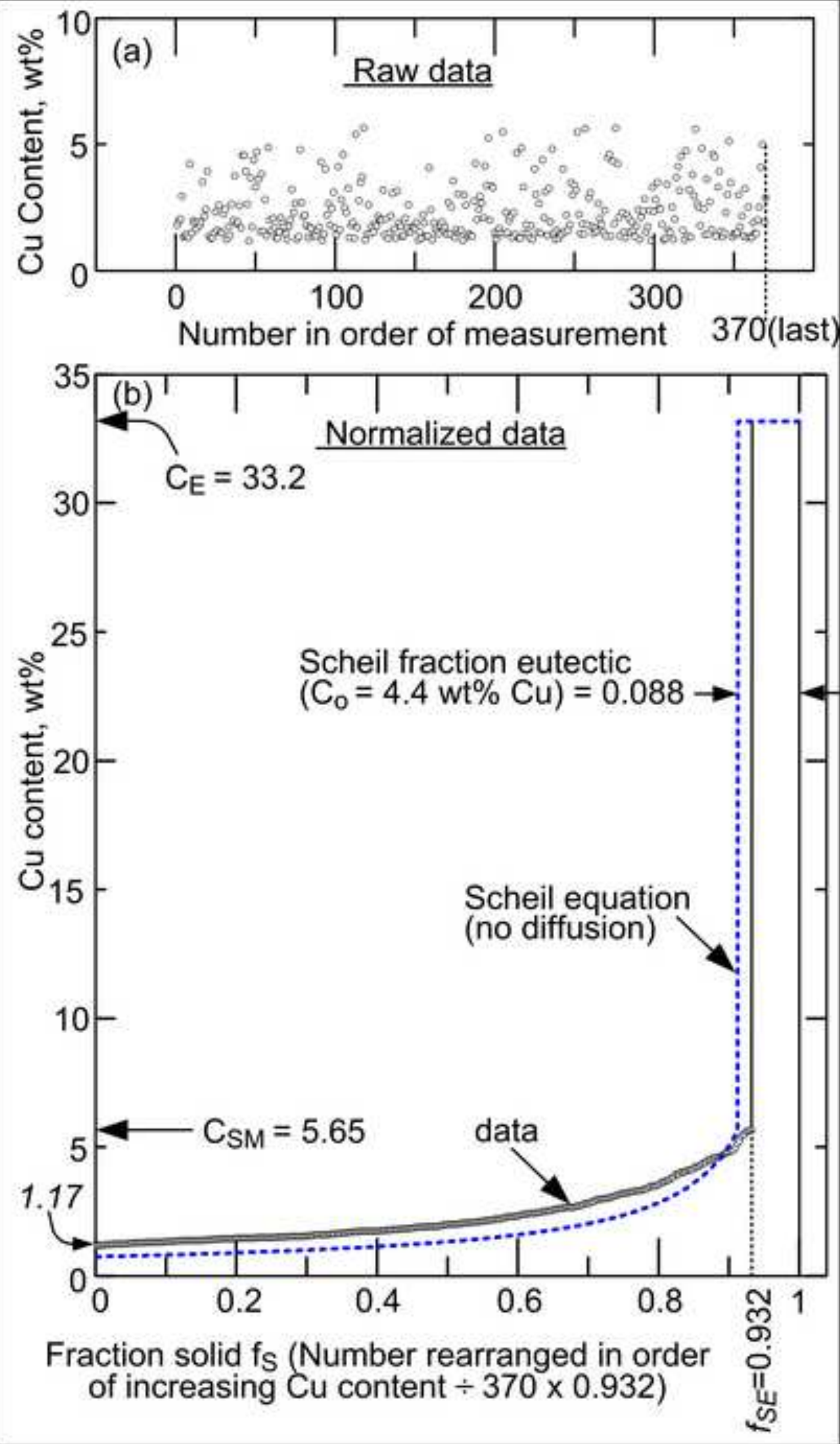


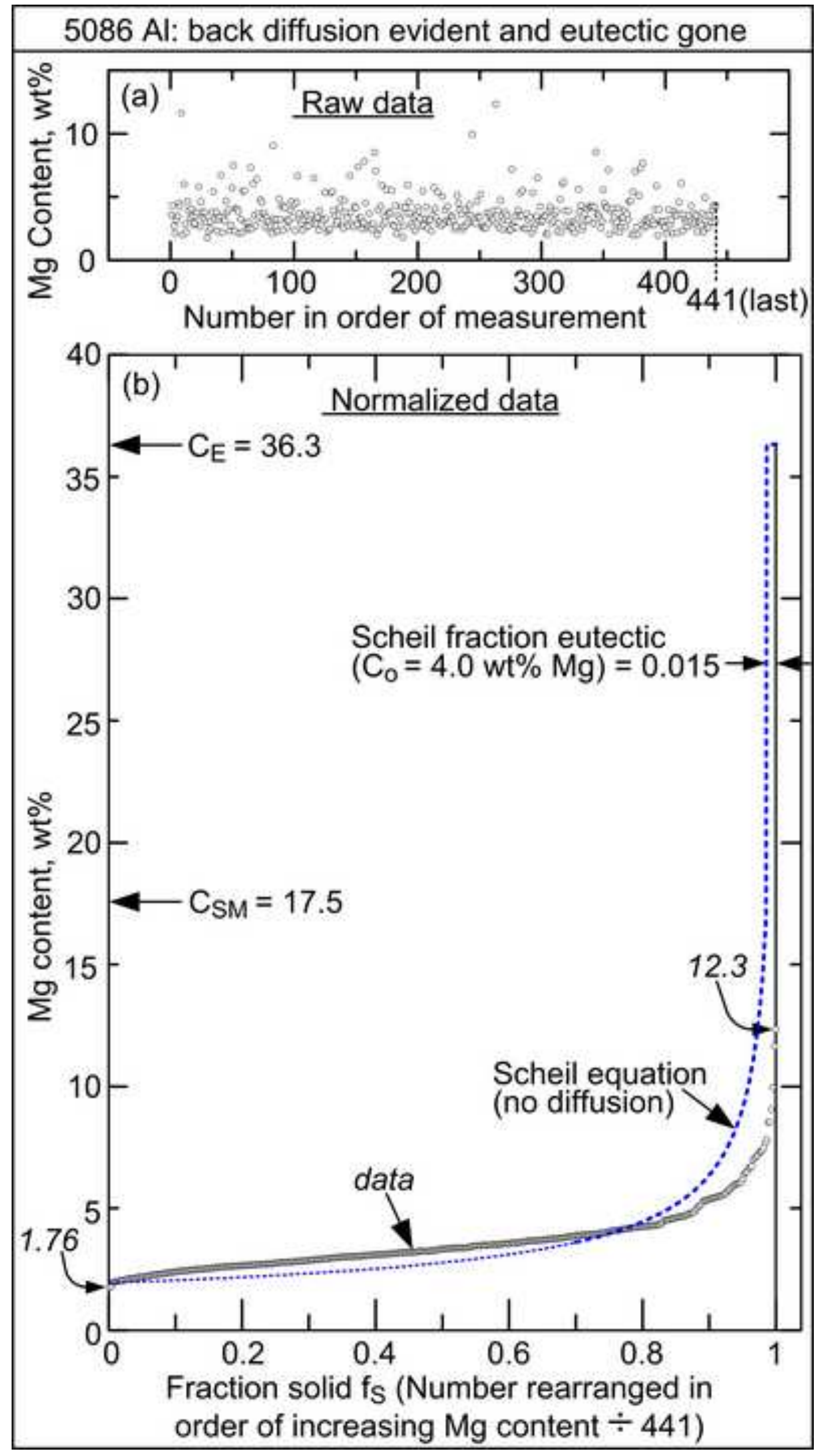




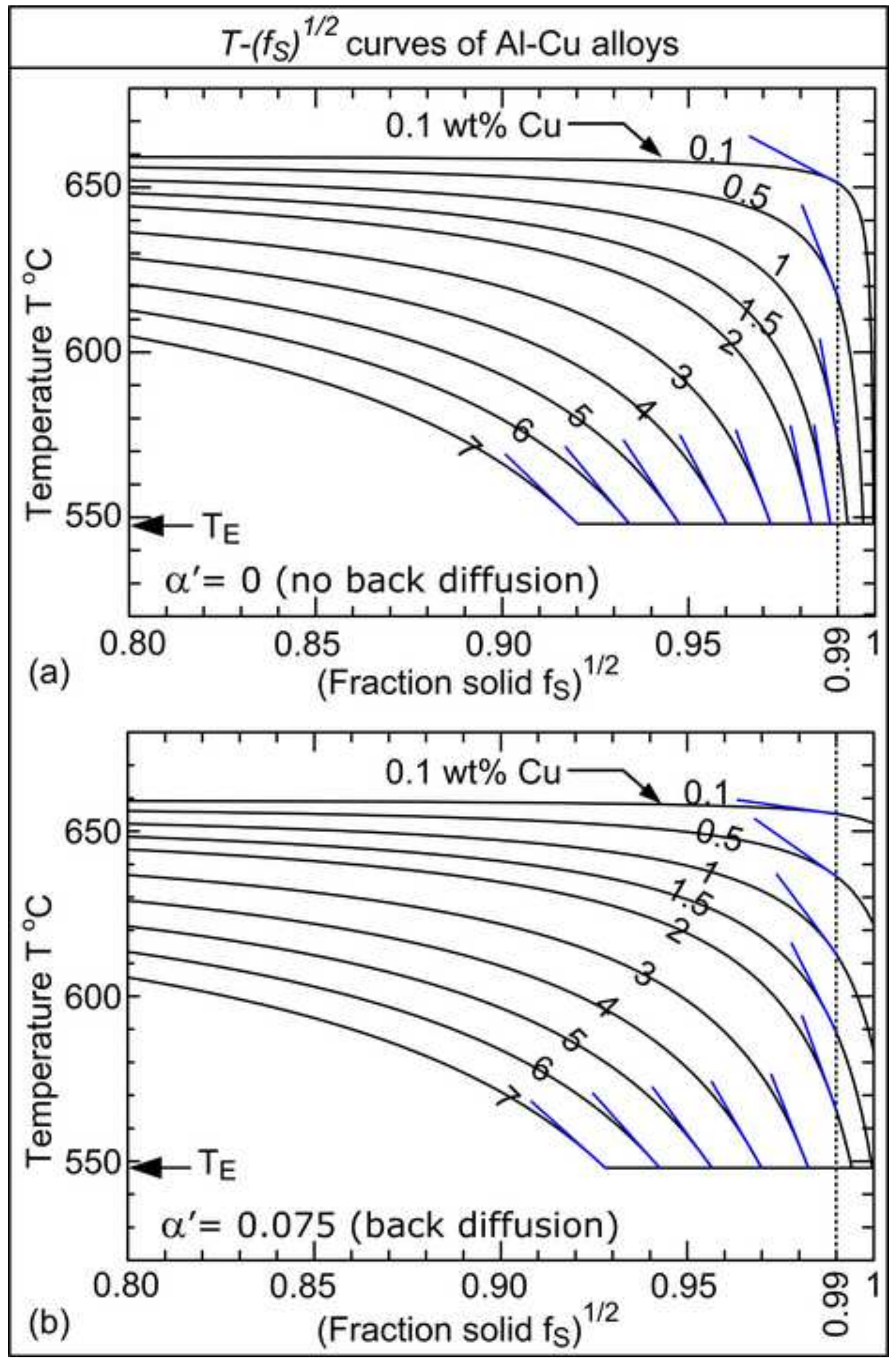



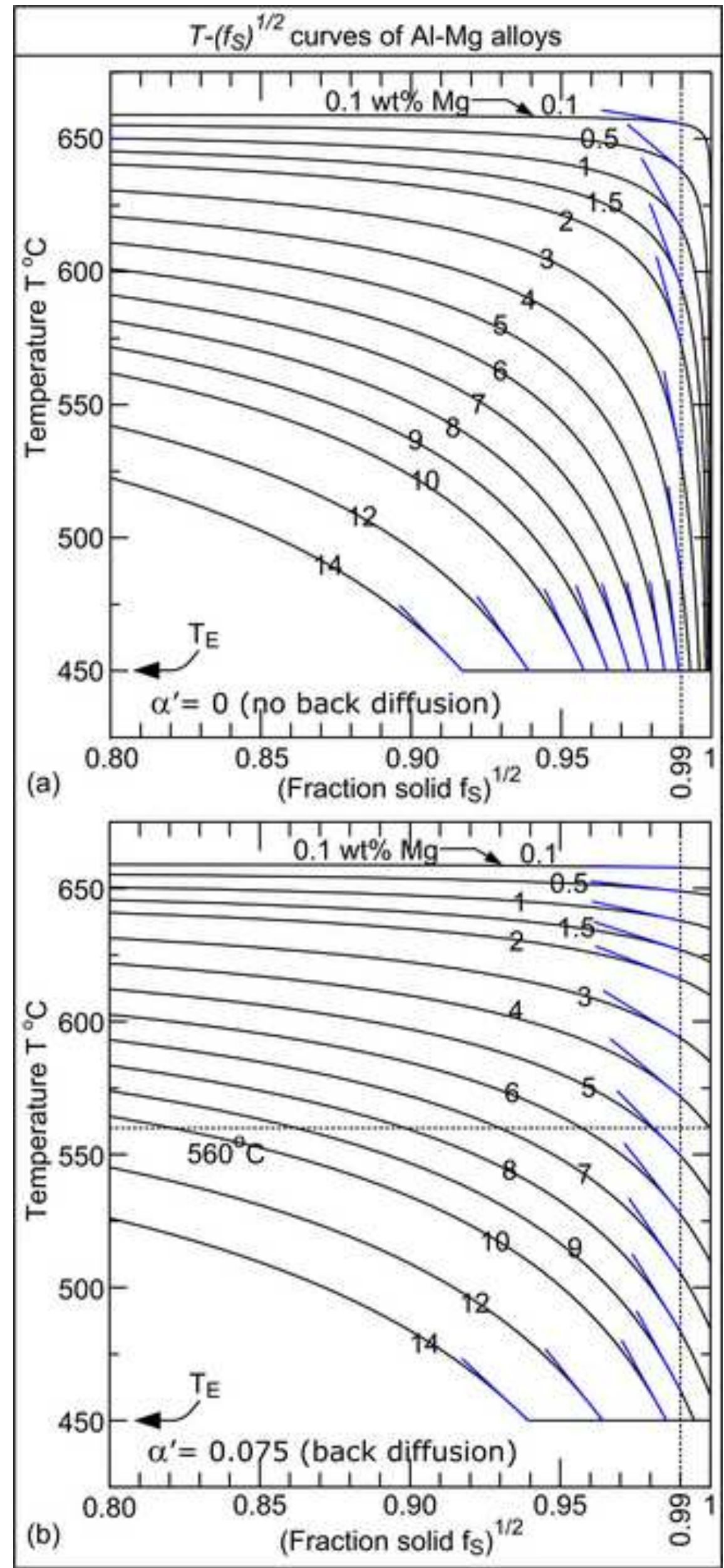


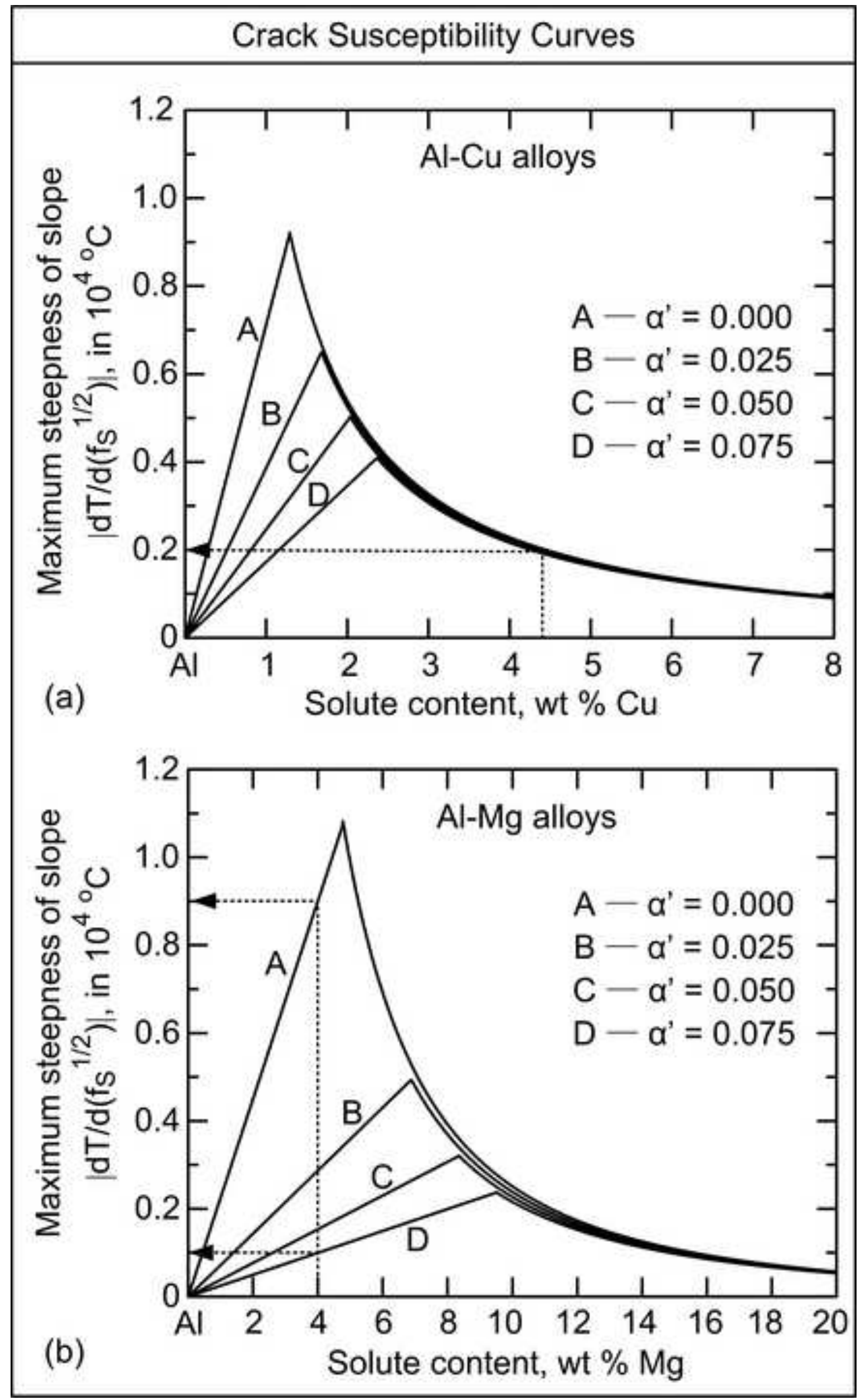


Graphic Abstract Al-Mg alloys, despite their wide freezing temperature range $\Delta T_{f}$, can have good resistance to cracking during solidification. To help explain why, the mushy zone of $5086 \mathrm{Al}(\sim \mathrm{Al}-4.0 \mathrm{Mg})$ was quenched during arc welding and the cooling curve measured to locate the beginning of the original mushy zone (liquidus temperature $T_{L}$ ) and the end (eutectic temperature $T_{E}$ ). Since little eutectic was visible just slightly behind the beginning of the quenched $5086 \mathrm{Al}$ mushy zone, little liquid was here in the original mushy zone, i.e., solidification already ended well above $T_{E}$. Since no dendrites were visible, either, and since the highest $\mathrm{Mg}$ content measured was well below the maximum solubility in solid $\mathrm{Al} C_{S M}(17.5 \mathrm{wt} \% \mathrm{Mg})$, microsegregation was mild here in the original mushy zone. These results suggest significant $\mathrm{Mg}$ back diffusion occurred during solidification (because of very high $C_{S M}$ ), causing: 1 . fraction solid $f_{S}$ to increase much faster with decreasing temperature $T, 2 . \Delta T_{f}$ to narrow down, and 3. dendritic grains to bond together extensively $\left(f_{S} \approx 1\right)$ to resist intergranular cracking earlier (well above $\left.T_{E}\right)$. Since $\left|d\left(f_{S}\right) / d T\right|$ increased, $\left|d T / d\left(f_{S}\right)^{1 / 2}\right|$ decreased to decrease the crack susceptibility index, i.e., the maximum $\left|d T / d\left(f_{S}\right)^{1 / 2}\right|$. All these changes caused by Mg back diffusion reduce the crack susceptibility. Calculated $T-\left(f_{S}\right)^{1 / 2}$ curve of Al-4.0Mg $(\sim 5086 \mathrm{Al})$ showed back diffusion reduces the index.

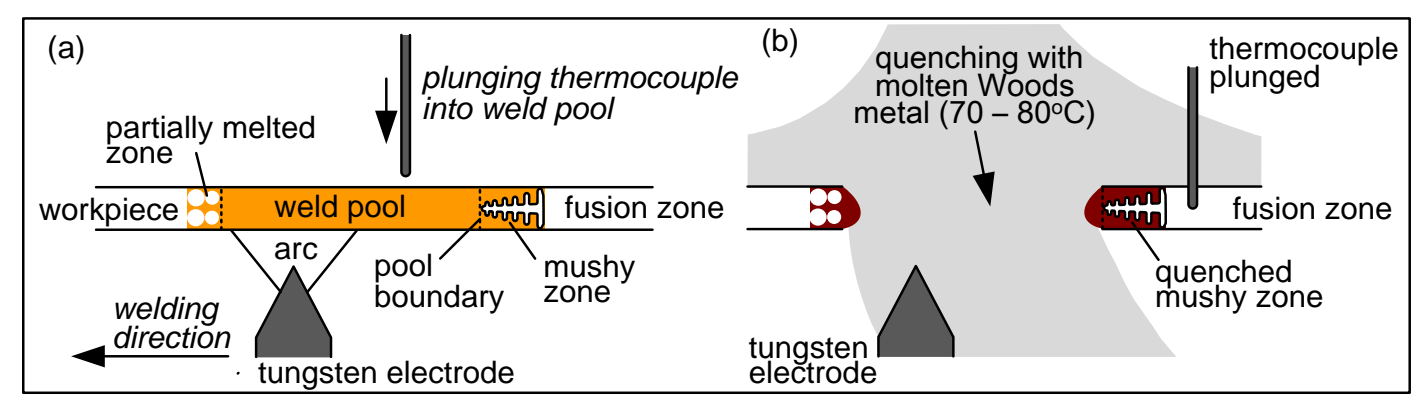

